\author{
Aus dem Fachbereich Medizin \\ der Johann Wolfgang Goethe-Universität \\ Frankfurt am Main
}

\author{
betreut am \\ Zentrum der Physiologie \\ Institut für Physiologie II \\ Direktor: Prof. Dr. Jochen Roeper
}

\title{
Neurotoxicities Associated with Immune Checkpoint Inhibitor Therapy
}

\author{
Dissertation \\ zur Erlangung des Doktorgrades der Medizin \\ des Fachbereichs Medizin \\ der Johann Wolfgang Goethe-Universität \\ Frankfurt am Main
}

vorgelegt von

Sophie Lan-Linh Duong

aus Darmstadt

Frankfurt am Main, 2021 
Dekan:

Referent:

Korreferent:

Tag der mündlichen Prüfung:
Prof. Dr. Stefan Zeuzem

Prof. Dr. Jochen Roeper

Priv. Doz. Dr. Dr. Michael Ronellenfitsch

30. November 2021 


\section{Table of Content}

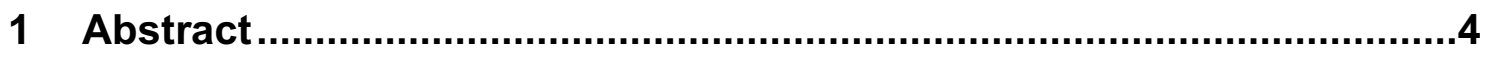

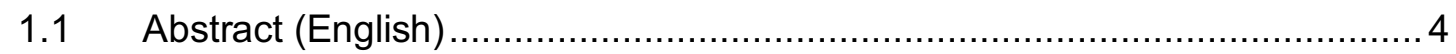

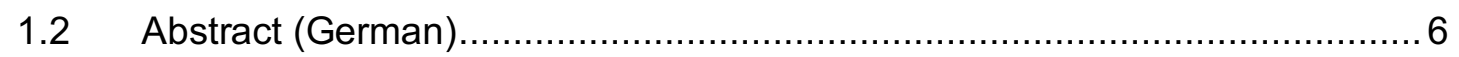

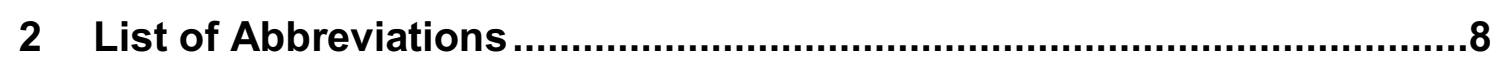

3 Comprehensive Summary of the Publication ...................................10

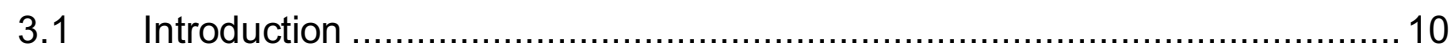

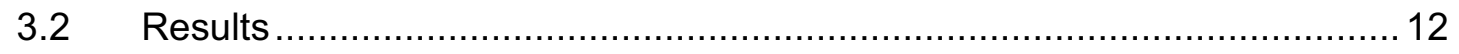

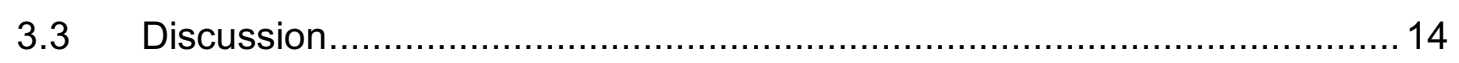

3.3.1 Prognostic marker for survival in patients with neurotoxicity ................... 14

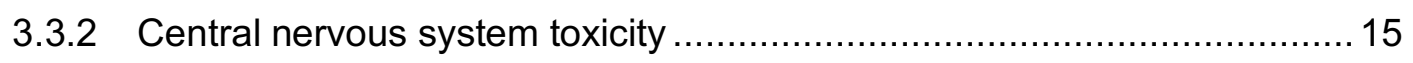

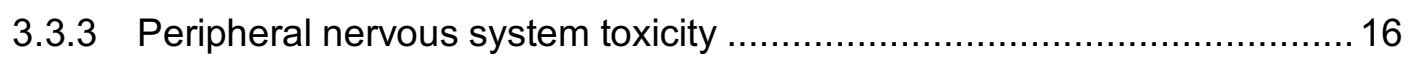

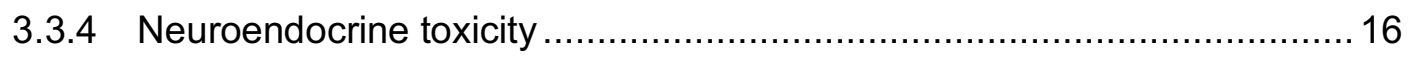

3.3.5 Diagnostic investigations of $\mathrm{ICl}$-induced neurotoxicity ........................... 17

3.3.6 Management of ICl-induced neurotoxicity............................................ 17

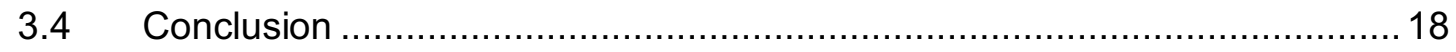

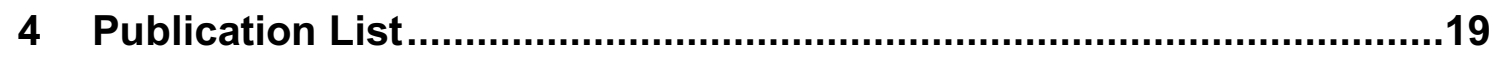

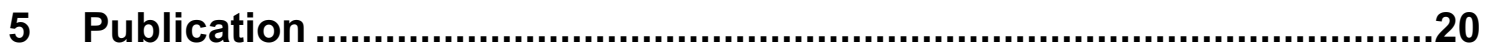

6 Detailed Declaration of Contributions to the Publication .....................33

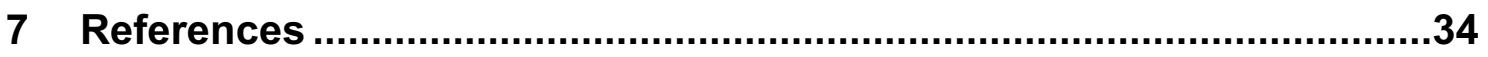

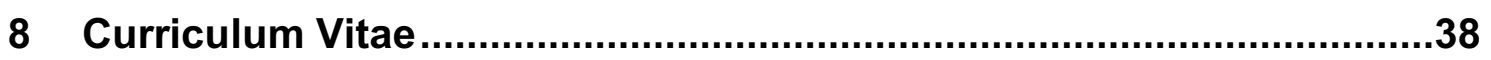

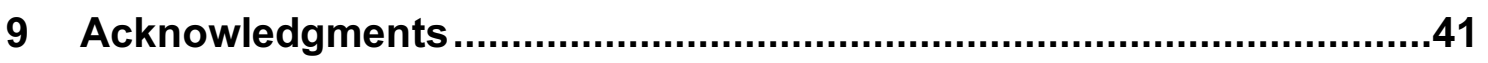

10 Schriftliche Erklärung ….......................................................................... 


\section{Abstract}

\subsection{Abstract (English)}

Cancer therapies have experienced significant advances in recent years. While conventional cytotoxic chemotherapy has long been the cornerstone for the treatment of many tumor entities, uprising immunotherapies have revolutionized the therapeutic landscape. Among them, immune checkpoint inhibitors (ICls) with their demonstrated increased overall survival rates and response rates in cancer patients are now FDA-approved for metastatic melanoma and multiple other malignancies. Despite their clinical benefit in cancer therapies, ICls can induce unique autoimmune-like toxicities known as immune-related adverse events (irAEs), which can involve any organ system including the nervous system. Although neurotoxicities are rare complications of $\mathrm{ICl}$ therapy they are often severe and can lead to long-term disability or even death if left untreated. Neurological irAEs exhibit a broad spectrum of clinical presentations affecting the entire nervous system. Diagnosing neurological irAEs is often challenging as symptoms and laboratory findings can be uncharacteristic for common neurological disorders and clinical experience with $\mathrm{ICl}$-mediated toxicities is still limited. In light of expanding clinical indications for ICls, physicians will encounter ICl-mediated neurotoxicities more frequently. Thus, thorough characterizations of the diverse set of neurological irAEs are essential for optimal patient care, the prevention of severe ICl-mediated complications, and the development of diagnostic and therapeutic algorithms. This work portrays the clinical presentation, management and outcome of neurological irAEs following $\mathrm{ICl}$ therapies.

Patients with neurotoxicities related to ICls who presented at the Yale New Haven Hospital between January 2014 and June 2018 were retrospectively identified from the quality control database. A comprehensive chart review was performed and data regarding patient demographics, medical history, ICI regimen and neurotoxicity were recorded. In total, 18 patients with neurological irAEs following $\mathrm{ICI}$ therapy for melanoma, small cell lung cancer, non-small cell lung cancer, and Merkel-cell carcinoma were identified. Neurotoxicities included central nervous system disorders comprising central demyelinating disorder, 
autoimmune encephalitis predominantly affecting the grey matter, and aseptic meningitis. Peripheral nervous system toxicities included sensorimotor polyneuropathy and myasthenia gravis. Cases of hypophysitis were also recorded. Time to onset of neurological irAEs ranged from 1 to72 weeks with a median of five weeks. In all patients ICls were held and steroids initiated. Additional immunomodulatory therapies were required in nine patients. Sixteen of 18 patients showed neurological improvement. Fourteen patients had highgrade neurotoxicity (grade 3-4), six of whom deceased due to cancer progression, while none of the low-grade neurotoxicity patients (grade 1-2) died. High-grade neurotoxicity was identified as a negative prognostic marker for overall survival $(p=0.046)$.

This work shows that neurotoxicities present early-onset, rapidly progressive complications of ICls with a broad spectrum of clinical phenotypes affecting the central nervous system, peripheral nervous system, and neuroendocrine system. A high index of caution for neurological irAEs is warranted throughout $\mathrm{ICl}$ therapy as timely diagnosis and management can reduce morbidity and mortality. Randomized clinical trials are needed to develop standardized diagnostic and therapeutic algorithms of $\mathrm{ICl}$-induced neurotoxicities. 


\subsection{Abstract (German)}

In den letzten Jahren wurden bei den therapeutischen Möglichkeiten von Tumorerkrankungen grundlegende Fortschritte erzielt. Während die konventionelle zytotoxische Chemotherapie lange Zeit Grundpfeiler in der Behandlung verschiedener Tumorentitäten war, hat der klinische Einsatz von Immuncheckpoint-Inhibitoren (ICl) die therapeutische Landschaft in den letzten Jahren revolutioniert. $\mathrm{ICI}$ zeigen hohe Überlebensraten und therapeutische Ansprechraten in Tumorpatienten*innen und sind bereits von der FDA zur Behandlung metastasierender Melanome sowie weiterer Malignitäten zugelassen. Trotz des klinischen Vorteils in der Tumortherapie können ICl zu autoimmun-ähnlichen Toxizitäten in allen Organsystemen, inklusive dem Nervensystem führen. Diese werden als immun-vermittelten Nebenwirkungen (irAEs) bezeichnet. Obwohl ICl-vermittelte Neurotoxizitäten selten sind, verlaufen sie häufig schwer und können zu langfristigen Schäden und sogar Todesfällen führen. Neurologische irAEs zeigen ein breites Spektrum klinischer Präsentationen und manifestieren sich im gesamten Nervensystem. Aufgrund der häufig unspezifischen Symptome und Laborveränderungen, die einem definierten neurologischen Syndrom oft nicht eindeutig zugeordnet werden können, ist die Diagnosestellung herausfordernd und die klinische Erfahrung mit ICl-induzierten Neurotoxizitäten weiterhin limitiert. In Anbetracht des zunehmenden klinischen Einsatzes von $\mathrm{ICl}$ werden behandelnde Ärzt ${ }^{*} i n n e n$ häufiger mit neurologischen irAEs konfrontiert werden. Eine genaue Charakterisierung ICl-vermittelter Neurotoxizität ist entscheidend für eine optimale Patientenversorgung sowie die Entwicklung diagnostischer und therapeutischer Algorithmen. Diese Arbeit analysiert den klinischen Phänotyp, das Management und das Outcome ICl-vermittelter Neurotoxizität.

Patienten mit Neurotoxizitäten infolge von $\mathrm{ICl}$, die im Yale New Haven Hospital zwischen Januar 2014 und Juni 2018 vorstellig waren, wurden durch eine retrospektive Recherche der qualitätskontrollierten Datenbank identifiziert. Es folgte eine umfassende Analyse der Patientenakten, bei der Daten bezüglich Patientendemographie, medizinischer Krankengeschichte, ICI Therapieschema und Neurotoxizität erfasst wurden. 
Insgesamt wurden 18 Patienten mit Neurotoxizität infolge von ICI Therapie zur Behandlung verschiedener Tumorerkrankung, inklusive des Melanoms, des kleinzelligen und nicht-kleinzelligen Lungenzellkarzinoms und des Merkel-ZellKarzinoms, identifiziert. Neurotoxizitäten umfassten zentral demyelinisierende Erkrankungen, Autoimmunenzephalitiden mit vorwiegender Affektion der grauen Substanz, die aseptische Meningitis, sensomotorische Polyneuropathien, Myasthenia gravis und Hypophysitiden. Die mediane Zeit bis zum Auftreten neurologischer irAEs betrug fünf Wochen (Intervall 1-72). Bei allen Patienten wurde die Therapie mit ICI pausiert und eine immunsuppressive Therapie mit Kortikosteroiden begonnen. Eine zusätzliche immunmodulatorische Therapie war bei neun Patienten erforderlich. Insgesamt sprachen 16 von 18 Patienten auf die immunsuppressive Therapie an. Von allen 14 Patienten, die schwere Neurotoxizität (Grad 3-4) entwickelten, verstarben sechs bis zum Ende des Beobachtungszeitraums, während keiner der Patienten mit leichter Neurotoxizität (Grad 1-2) verstarb. Schwere Neurotoxizität wurde als negativer prognostischer Marker für die Gesamtüberlebensdauer identifiziert $(p=0.046)$.

Neurotoxizitäten sind früh manifestierende, rasch progrediente Komplikationen unter ICI Therapie mit einem breiten Spektrum an klinischen Präsentationen, welche das zentrale und periphere Nervensystem sowie das neuroendokrine System betroffen können. Ein hohes Maß an Aufmerksamkeit für neurologische irAEs ist während sowie nach ICI Therapie geboten, um zeitnah diagnostische und therapeutische Maßnahmen zur Prävention substantieller Morbidität und Mortalität einzuleiten. Randomisierte prospektive klinische Studien sind notwendig, um standardisierte diagnostische und therapeutische Algorithmen für ICl-vermittelte Neurotoxizitäten zu entwickeln. 


\section{List of Abbreviations}

A Atezolizumab

AChR Acetylcholine receptor

АCTH Adrenocorticotropic hormone

AGNA-1 Anti-glial nuclear antibody type 1

ADEM Acute demyelinating encephalomyelitis

AEGM Autoimmune encephalitis predominantly affecting the grey matter

AID Autoimmune disorder

CK Creatine kinase

CNS Central nervous system

CSF Cerebral spinal fluid

CTCAE Cancer Institute's Common Terminology Criteria for Adverse Events

CTE Number of cycles to neurotoxicity event

CTLA-4 Cytotoxic T-lymphocyte-associated antigen 4

DM1 Diabetes mellitus type 1

ECG Electrocardiogram

EEG Electroencephalography

EMG Electromyography

FDA U.S. Food and Drug Administration

GAD65 Glutamic acid decarboxylase 65 antibody

GKRS Gamma knife radiosurgery

I Ipilimumab

ICI Immune checkpoint inhibitor

ICU Intensive care unit

IrAEs Immune-related adverse events

IV Intravenous

IVIG Intravenous immune globulin

LDH Lactate dehydrogenase

MG Myasthenia gravis

Mo Months

MP Methylprednisolone

MRI Magnetic resonance imaging 


\begin{tabular}{ll} 
MS & Multiple sclerosis \\
N & Nivolumab \\
NA & Not available \\
NCS & Nerve conduction study \\
NSCLC & Non-small cell lung cancer \\
NTX & Neurotoxicity \\
OCB & Oligoclonal bands \\
OS & Overall survival \\
P & Pembrolizumab \\
PD-1 & Programmed cell death 1 \\
PD-L1 & Programmed cell death ligand 1 \\
PND & Paraneoplastic neurological disorders \\
PNP & Paraneoplastic \\
PNS & Peripheral nervous system \\
RNS & Repetitive nerve stimulation \\
SCLC & Small cell lung cancer \\
SPEP & Serum protein electrophoresis \\
TSH & Thyroid-stimulating hormone \\
WBC & White blood count \\
WNL & Within normal limits \\
Y & Years \\
\hline
\end{tabular}




\section{Comprehensive Summary of the Publication}

\subsection{Introduction}

Immune checkpoint inhibitors (ICls) are powerful immunotherapeutic agents that have transformed cancer therapy. ${ }^{1}$ They have shown high response rates in patients with metastatic melanoma and various other advanced malignancies. ICls are now FDA-approved for melanoma, non-small cell lung cancer (NSCLC), urothelial cancer and head and neck cancers, among others..$^{2-5}$ Due to the expanding trial landscape for ICls, their clinical indication is expected to grow. ${ }^{6}$

$\mathrm{ICls}$ are monoclonal antibodies that promote an immune response against tumor-specific antigens by blocking coinhibitory regulators of T-cell activation. ${ }^{7}$ Identified binding targes of $\mathrm{ICls}$ include the coinhibitory immune checkpoint receptors cytotoxic T-lymphocyte-associated antigen 4 (CTLA-4), programmed cell death 1 (PD-1), and its ligand, programmed cell death ligand 1 (PD-L1). While CTLA-4 is found on activated T cells, PD-1 is expressed on activated T cells, B cells, monocytes, and natural killer cells. ${ }^{8,9}$ PD-L1 is expressed on antigen presenting cells and has further been identified in several cancer cells. ${ }^{10}$ The CTLA-4 and PD-1/PD-L1 pathways are essential for maintaining peripheral immune tolerance. Activating these pathways inhibits T-cell function via a negative feedback mechanism, thereby preventing autoimmunity. ${ }^{11,12}$ Various tumor cells can hijack and potentiate CTLA-4 and PD-1/PD-L1 signaling which leads to T-cell exhaustion. Escaping T-cell mediated immune destruction enables unchecked cancer proliferation and survival. ${ }^{7,10}$

$\mathrm{ICls}$ interfere with these interactions and antagonize the inhibitory signal, which potentiates a destructive antitumor $\mathrm{T}$ cell immune response. ${ }^{13}$ Yet, the upregulation of immune pathways by $\mathrm{ICls}$ is unspecific. The administration of ICls therefore pose the risk of provoking immune-related adverse events (irAEs). ${ }^{14}$ Possible pathophysiological mechanisms of irAEs include: (i) the activation of T-cells with cross-reactivity between tumor antigens and endogenous antigens, (ii) the direct effect of ICls binding to tissue antigens, (iii) the increased B-cell-mediated autoantibody production, and (iv) the increased production of pro-inflammatory cytokines. ${ }^{15}$ 
The spectrum of $\mathrm{ICI}$-mediated irAEs is broad. Any organ system can potentially be affected. The most commonly observed irAEs involve the skin, the gastrointestinal tract, the liver, and the endocrine system. For example, melanoma-associated hypopigmentation, colitis, hepatitis and thyroid dysfunction have been linked to $\mathrm{ICI}$ therapy. ${ }^{16}$ While neurological irAEs are relatively rare complications of ICls, they can be particularly severe compared to irAEs in other organ systems and can even be life-threatening if left undiagnosed or untreated..$^{17,18}$ The cumulative incidence of ICI-mediated neurotoxicities has been reported to be approx. 3.8 \% with anti-CTLA-4, 6.1\% with anti-PD-1 and $12.0 \%$ with combination therapy, with severe neurotoxicities occurring in less than $1.0 \%$ of all cases.${ }^{17}$ Neurotoxicities can involve the entire nervous system, including the central nervous system (CNS), the peripheral nervous system (PNS), and the neuroendocrine system. ${ }^{17}$

At present, there is a paucity of literature regarding the clinical characteristics and long-term sequelae of $\mathrm{ICl}$-induced neurotoxicities. Current practical guidelines for the management of neurological irAEs are mostly derived from clinical observations and based on expert consensus. ${ }^{19}$ Diagnosing $\mathrm{ICl}-$ mediated neurotoxicities is often challenging due to uncharacteristic symptoms and laboratory changes. Neurological irAEs should be categorized following existing diagnostic groups, although they might constitute their own disease entity requiring specific diagnostic and therapeutic algorithms.

The intensified application of ICls for cancer therapies is expected to increase the prevalence of neurotoxicities. Clinicians need to be aware of treatmentrelated symptoms and their appropriate management to systematically reduce morbidity and mortality. The present work characterizes neurological irAEs, their clinical presentation, diagnostic findings, management, overall outcome, and prognostic markers. Further defining the clinical spectrum of ICl-mediated neurotoxicities will pave the way to raise awareness among treating physicians and foster early disease management to keep leveraging the advantages of $\mathrm{ICls}$ at a much reduced patient risk. 


\subsection{Results}

In the present work 18 patients with neurotoxicity following anti-PD-1 (pembrolizumab, nivolumab), anti-PD-L1 (atezolizumab) or anti-CTLA-4 (ipilimumab) therapy were retrospectively identified from the database of the Section of Neuro-Oncology and the Neuromuscular Clinic of the Department of Neurology at the Yale School of Medicine. Most neurotoxicities were reported following combination therapy with ipilimumab and nivolumab $(n=7)$, followed by anti-PD-1/PD-L1 and anti-CTLA-4 monotherapy. Melanoma was the most frequently observed cancer $(n=10)$. Patients further received ICls for SCLC, NSCLC and Merkel-cell carcinoma. Neurotoxicities occurred after a median of 5 weeks (range 1-72) of ICI therapy. Neurotoxicities were graded according to the National Cancer Institute's Common Terminology Criteria for Adverse Events (CTCAE) version 5.0.20 The scale spans five grades of increasing severity, corresponding to mild (1), moderate (2), severe (3), life-threatening (4) and death related to adverse events (5). Low-grade neurotoxicity was defined as grade 1 and 2 and high-grade neurotoxicity comprised grade 3 and 4 . Highgrade neurotoxicity developed in 14 patients, three of whom had a preexistent neurological autoimmune disorder (AID), including myasthenia gravis (MG) and multiple sclerosis (MS). Low-grade neurotoxicities developed in four patients. Fifteen patients experienced other concurrent non-neurological irAEs.

CNS disorders predominated the patient population $(n=9)$ and comprised central demyelinating disorders $(n=5)$, autoimmune encephalitis predominantly affecting the grey matter (AEGM, $n=3)$, and aseptic meningitis $(n=1)$. Central demyelinating disorders included three cases of high-grade neurotoxicity, presenting as an exacerbation of MS in a patient with known relapsing-remitting $\mathrm{MS}$, optic neuritis, and acute demyelinating encephalomyelitis (ADEM). The remaining two cases were low-grade neurotoxicity, including a demyelinating overlap syndrome and focal demyelinating encephalitis. While magnetic resonance imaging (MRI) findings consistent with demyelination aided in the diagnosis, brain biopsy was required in two cases to confirm demyelination and exclude brain metastasis or radiation necrosis. 
AEGM were all high-grade neurotoxicities. In one patient glutamic acid decarboxylase 65 antibody (GAD65) was detected in the serum, another had paraneoplastic anti-glial nuclear antibody type 1 (AGNA-1) in the cerebral spinal fluid (CSF), and the third patient remained antibody negative. All patients presented with subacute encephalopathy.

Finally, aseptic meningitis was identified as high-grade CNS toxicity. The patient presented with fever and headache. CSF revealed mild lymphocytic pleocytosis with elevated protein levels without the detection of a viral or bacterial infection.

PNS toxicities comprised sensorimotor peripheral neuropathy $(n=2)$, MG $(n=$ 3 ) and MG with concomitant myositis and myocarditis $(n=1)$.

Peripheral neuropathies were all high-grade neurotoxicity and diagnosis was based on clinical exam findings, demonstrating gait ataxia, areflexia, and diminished sensation in the lower extremities and electrodiagnostic findings supportive of sensorimotor axonal-demyelinating polyneuropathies. Although one patient received previous platinum-based chemotherapy, the onset of polyneuropathy immediately after $\mathrm{ICl}$ initiation supported an immune-mediated pathogenesis.

All four patients with ICI-mediated MG had high-grade neurotoxicity, three of whom were positive for anti-acetylcholine receptor antibodies (anti-AChR). The main presenting symptoms were generalized muscle weakness and fatigability. Two seropositive patients progressed to severe myasthenic crisis requiring ICU admission and ventilatory support for respiratory weakness. One seropositive MG patient had overlapping myositis and myocarditis. In the case of seronegative generalized MG, diagnosis was supported by electrophysiologic findings demonstrating decrement in repetitive nerve stimulation.

Low-grade $\mathrm{ICl}$-induced hypophysitis $(n=3)$ was observed following anti-CTLA-4 monotherapy or combination therapy for metastatic melanoma. Commonly reported symptoms were fatigue, headache, insomnia, confusion, and proximal muscle weakness. Decreased serum levels of pituitary hormones supported the diagnosis of hypophysitis-induced anterior pituitary insufficiency. MRI of the 
brain was performed to rule out metastasis and in one case MRI findings were consistent with pituitary inflammation.

In all patients, ICls were discontinued followed by corticosteroid therapy. Additional immunosuppression was administered with infliximab $(n=1)$ and intravenous immunoglobulins (IVIG, $n=9$ ). Neurotoxicities completely resolved in five patients, partially resolved in 11 patients, and persisted in the two remaining patients with $\mathrm{ICl}$-induced polyneuropathy. Long-term therapy comprising monthly IVIG and daily oral pyridostigmine for MG or hormone substitution for anterior pituitary insufficiency was required in six patients.

Twelve patients were alive at database closure. The remaining six patients, all with high-grade irAEs, had died due to cancer progression. Overall survival estimates from $\mathrm{ICl}$ infusion to death of any cause or last follow-up were calculated along with predictors of outcome using Kaplan-Meier survival analysis and log-rank test. The significance level was set to $p \leq 0.05$ for all tests. Median follow-up was 19 months (range 2-80). Presentation with highgrade neurotoxicity (grade $3-4, n=14$ ) negatively impacted OS $(p=0.046)$ when compared to patients with low-grade neurotoxicity (grade 1-2, $n=4$ ).

\subsection{Discussion}

This work characterizes the clinical spectrum of neurological irAEs based on a patient cohort with a diverse set of neurotoxicities, affecting the CNS, the PNS and the neuroendocrine system. The results suggest that $\mathrm{ICl}$-induced neurotoxicities may increase morbidity and mortality.

\subsubsection{Prognostic marker for survival in patients with neurotoxicity}

High-grade neurotoxicity is identified as a negative prognostic indicator for OS. Although the ultimate cause of death in patients with high-grade neurotoxicities was progression of the underlying cancer, this finding suggests that high-grade neurotoxicity may impact OS due to uncontrolled tumor progression in response to $\mathrm{ICI}$ discontinuation. The role of neurotoxicities emphasize the importance of 
optimized therapeutic algorithms to overcome neurotoxicities without impairing cancer therapies.

\subsubsection{Central nervous system toxicity}

CNS disorders are rare complications of ICls with an estimated incidence ranging from $0.4 \%$ to $1.0 \% .{ }^{21}$ Clinical studies investigating $\mathrm{ICl}$-induced CNS disorders are sparse and most reported evidence is based on smaller case series and case reports. ${ }^{22-25}$ Previous studies predominantly reported neurotoxicities involving the PNS. ${ }^{17,26}$ This work extends the spectrum of known neurotoxicities by contributing several cases of CNS toxicities.

$\mathrm{ICl}$-induced central demyelinating disorders can develop de novo or as a flare of preexisting neurological AIDs. Relevant differential diagnoses include metastatic disease or radiation necrosis in recipients of gamma knife radiosurgery (GKRS). Radiographic distinction of these entities can be challenging ${ }^{27}$ and might require histopathologic investigation via brain biopsy as seen in this cohort. Increased rates of radiation necrosis after GKRS in patients with ICI therapy compared to cytotoxic chemotherapy have been reported. ${ }^{28}$ The mechanism by which ICls contribute to the development of radiation necrosis is not fully understood, yet most likely involves radiation-induced disruption of the blood brain barrier, resulting in the facilitated interaction of peripheral immune cells with neuronal antigens thus promoting an inflammatory response. ${ }^{29,30}$

$\mathrm{ICl}$-induced autoimmune encephalitis presented with an alteration in consciousness, confusion, memory dysfunction, accompanied by headaches, and hallucinations. Differential diagnoses are broad and include classic paraneoplastic neurological disorders (PND). In this work, the autoimmune antibody GAD-65 and paraneoplastic antibody AGNA-1 were identified in patients with encephalitis following $\mathrm{ICl}$ therapy. Whether $\mathrm{ICls}$ mount de novo autoimmunity or unmask preexisting autoimmune and paraneoplastic syndromes is still unknown. However, the detection of autoimmune encephalitis and paraneoplastic antibodies following $\mathrm{ICl}$ exposure suggests that these 
etiologies are not mutually exclusive. The frequency of anti-neuronal antibodies associated with $\mathrm{ICl}$-mediated encephalitis is currently underexplored as antibody diagnostics, including both serum and CSF paraneoplastic panel, are rarely reported. Determining a baseline serologic profile of patients with cancers commonly associated with paraneoplastic neurological disorders may aid in predicting the risk for developing these adverse events. The high mortality of encephalitis ${ }^{18}$ requires early recognition and appropriate intervention with corticosteroids as most of the cases are steroid-responsive.

\subsubsection{Peripheral nervous system toxicity}

The most commonly reported $\mathrm{ICl}$-induced PNS toxicities are peripheral neuropathies, followed by myasthenic syndromes. ${ }^{31-33}$

$\mathrm{ICl}$-induced peripheral neuropathies can cause axonal or demyelinating damage patterns and present acutely or subacutely. ${ }^{31}$ Peripheral neuropathies are often associated with long-term sequelae due to permanent motor or sensory deficits ${ }^{31}$ that are not responsive to steroid therapy as seen in this cohort.

MG is a severe complication of ICls with an estimated mortality rate of $30.4 \% .^{32}$ The risk for myasthenic crisis, overlapping myositis, and myocarditis is higher for neurological irAEs than for idiopathic MG. ${ }^{26,33,34}$ Especially immunemediated myocarditis is associated with a severe clinical course and high mortality. ${ }^{35}$ Patients with ICl-mediated MG often show residual neurological symptoms requiring long-term immunomodulatory therapy and in some cases additional symptomatic therapy with pyridostigmine. ${ }^{33}$

\subsubsection{Neuroendocrine toxicity}

Hypophysitis is a more common $\mathrm{ICl}$-induced neuroendocrine toxicity with an estimated incidence of $3.3 \%$, especially following anti-CTLA-4 therapy used singly or in combination. ${ }^{36}$ Clinical presentation of consequent hypopituitarism includes fatigue, dizziness, and headache. Often, anterior pituitary insufficiency is permanent, requiring long-term hormonal substitution. ${ }^{37}$ 


\subsubsection{Diagnostic investigations of ICl-induced neurotoxicity}

The timely diagnosis of $\mathrm{ICl}$-induced neurotoxicities is complicated by the clinical presentation and diagnostic findings that are unspecific and do not necessarily fit the typical characteristics of defined neurological syndromes. Important differential diagnoses include cancer progression, paraneoplastic syndromes, metabolic disorders, infections, or complications related to other non- $\mathrm{ICl}$ therapies. Diagnostic evaluations of neurological irAEs should include MRI studies as imaging abnormalities demonstrating leptomeningeal enhancement, enlargement, or enhancement of the anterior pituitary gland or demyelination were described in aseptic meningitis, hypophysitis, and central demyelinating disorders, respectively. Further, imaging studies were used to exclude alternative diagnoses for the observed neurological symptoms, especially metastatic diseases. CSF analysis may further aid in the diagnosis of $\mathrm{ICl}-$ induced CNS disorders, revealing lymphocytic pleocytosis or elevated protein levels in aseptic meningitis or encephalitis.

\subsubsection{Management of ICl-induced neurotoxicity}

Patients need to be educated about symptoms related to ICI-mediated neurotoxicities and understand that the timing of presentation is highly variable, ranging from a few weeks to several months from $\mathrm{ICl}$ initiation and can occur even after discontinuation of $\mathrm{ICI}$ therapy. ${ }^{38}$ However, this work demonstrates that an early presentation within a few weeks after $\mathrm{ICl}$ infusion is more common. These observations highlight the importance of constant vigilance for signs and symptoms of neurotoxicities throughout and after cessation of ICI therapy.

The most important measures to reduce morbidity and mortality in patients treated with ICls are close clinical monitoring and adequate adverse event management. Multinational and multidisciplinary organizations such as the American Society of Clinical Oncology (ASCO) have developed comprehensive therapeutic outlines for $\mathrm{ICl}$-induced toxicities to facilitate diagnosis and management. ${ }^{19}$ Specific therapies depend on the respective phenotype and severity of the neurotoxicity. Steroids are the mainstay of therapy, as most 
neurological irAEs are responsive to steroids. ${ }^{26}$ The timely resolution of neurological symptoms to steroids can further aid in diagnosing an $\mathrm{ICl}$-mediated etiology. As most of the patients in this cohort had improvements of their neurological symptoms upon holding ICls and commencing steroids, a low threshold to begin immunosuppressive measures in patients with grade $>1$ neurotoxicities should be established. In certain steroid-refractory cases, permanent drug cessation or additional IVIG, plasmapheresis or more aggressive immunosuppressants may be indicated to prevent permanent damage to the nervous system. ${ }^{19,26}$ Treatment algorithms optimizing neurological outcome without compromising the effect of cancer therapy remain to be established. With respect to the latter, until now there has been no clear evidence that systemic steroid therapy affects the anticancer effect of ICls or negatively impacts overall survival in oncologic patients with irAEs. ${ }^{39,40}$

\subsection{Conclusion}

In conclusion, ICls can induce severe, potentially long-lasting and lifethreatening neurological irAEs. In the era of emerging immunotherapies for cancers, neurological irAEs will be more frequently encountered and increasingly recognized. Defining the broad spectrum of neurotoxicities is warranted to facilitate diagnosis and management of irAEs for an optimized patient outcome. Randomized prospective studies are needed to develop diagnostic and treatment algorithms to provide optimized patient care. Predictive biomarkers would help to identify patients at risk for severe immunemediated neurotoxicity. 


\section{Publication List}

Duong SL, Barbiero FJ, Nowak RJ, Baehring JM. Neurotoxicities associated with immune checkpoint inhibitor therapy. J Neurooncol. 2021 Apr;152(2):265277. doi: 10.1007/s11060-021-03695-w.

Duong SL, Zierold S, Kramer R, Reincke M, Kerl-French K, Boehmerle W, Pavel M, Weckbach L, French LE, Knauss S, Heinzerling L. Spätfolgen nach Immuntherapie. Onkologe (2021). doi: 10.1007/s00761-021-00946-3.

Kuo IY, Duong SL, Nguyen L, Ehrlich BE. Decreased Polycystin 2 Levels Result in Non-Renal Cardiac Dysfunction with Aging. PLoS One. 2016 Apr 15;11(4):e0153632. doi: 10.1371/journal.pone.0153632. 


\title{
Neurotoxicities associated with immune checkpoint inhibitor therapy
}

\author{
Sophie L. Duong ${ }^{1,2}$ · Frank J. Barbiero ${ }^{1} \cdot$ Richard J. Nowak ${ }^{1}$ Joachim M. Baehring ${ }^{3,4} \oplus$
}

Received: 15 October 2020 / Accepted: 4 January 2021

(c) The Author(s), under exclusive licence to Springer Science+Business Media, LLC part of Springer Nature 2021

\begin{abstract}
Introduction Immune checkpoint inhibitors (ICIs) have emerged as a promising class of cancer immunotherapies. Neurotoxicities are uncommon, but often severe, and potentially fatal complications of ICIs, and clinical experience is limited. The aim of this study is to further define the clinical spectrum and outcome of ICI-mediated neurotoxicities.

Methods Patients with ICI-associated neurotoxicities were identified from retrospective review of the quality control database at a single institution. Data regarding demographics, medical history, clinical presentation, diagnosis, management and outcome were recorded.

Results We identified 18 patients with neurotoxicity following ICI therapy with pembrolizumab, nivolumab, atezolizumab, or ipilimumab for a diverse set of malignancies. Neurotoxicities comprised central demyelinating disorder (28\%), autoimmune encephalitis predominantly affecting the grey matter (17\%), aseptic meningitis (6\%), myasthenia gravis (MG) (17\%) with concurrent myositis (6\%), sensorimotor polyneuropathy (11\%) and hypophysitis (17\%). Median time to onset of neurotoxicities was 5 weeks (range 1-72). All patients discontinued ICIs and received steroids with additional immunomodulation required in 9 patients, resulting in improvement for 16 of 18 patients. Grade 3-4 neurotoxicity developed in 14 patients, of whom 6 had died at database closure. Grade 3-4 severity negatively impacted overall survival (OS) $(p=0.046)$.

Conclusions ICI-mediated neurotoxicities present early, are rapidly progressive and include a diverse phenotype affecting the CNS, PNS and neuroendocrine system. A high level of vigilance is warranted, as early diagnosis and targeted treatment can substantially prevent morbidity and mortality. Prospective clinical trials are warranted to assess optimized management of ICI-induced neurotoxicities.
\end{abstract}

Keywords Neurologic immune-related adverse events · Immunotherapy · Cancer · PD1 · CTLA4

\section{Introduction}

Immune checkpoint inhibitors (ICIs) have emerged as a potent class of immunotherapeutic agents and are now FDAapproved for an increasing number of advanced malignancies [1-3]. Further ongoing trials are anticipated to expand

Joachim M. Baehring

joachim.baehring@yale.edu

1 Department of Neurology, Yale School of Medicine, New Haven, CT, USA

2 Institute of Neurophysiology, Goethe University Frankfurt, Frankfurt, Germany

3 Department of Neurosurgery, Yale School of Medicine, New Haven, CT, USA

4 Division of Neuro-Oncology, Department of Neurology, Yale School of Medicine, 15 York Street LLCI 912, PO Box 208028, New Haven, CT 06520-8082, USA their indications [4]. ICIs constitute monoclonal antibodies that block negative regulators of $\mathrm{T}$ cell activation by targeting the cytotoxic $\mathrm{T}$ lymphocyte-associated antigen 4 (CTLA-4), programmed cell death 1 (PD-1) and its ligand programmed cell death ligand 1 (PD-L1). This process potentiates a destructive antitumor $\mathrm{T}$ cell immune response [5]. Given their mechanism of action it has come as no surprise that unique autoimmune toxicities, termed immunerelated adverse events (irAEs) have been described in ICI recipients [6]. ICI-related neurotoxicities are uncommon and the reported cumulative incidence of severe neurotoxicities is estimated at less than 1\% [7]. Neurotoxicities can involve the CNS, the PNS and the neuroendocrine system and may be associated with substantial morbidity and mortality if left untreated [7-10]. At present, the pathogenesis of ICIrelated neurotoxicities has not been fully understood and data regarding the clinical characteristics and long-term outcome are limited with most evidence derived from isolated 
case reports and small case series [11-14]. This study characterizes patients who presented to the Yale New Haven Hospital with neurotoxicities related to ICIs. We describe the clinical presentation, management and overall outcome of ICI-induced neurotoxicities to further define the diverse toxicity profile of ICIs.

\section{Material and methods}

\section{Patient selection}

We identified patients with neurotoxicities following treatment with ICIs targeting PD-1 (pembrolizumab, nivolumab), PD-L1 (atezolizumab) or CTLA-4 (ipilimumab) from the quality control database of the Section of Neuro-Oncology, Yale Cancer Center, New Haven, CT and the Neuromuscular Clinic, Department of Neurology, Yale School of Medicine using the keywords: "PD-L1", "PD-1", "pembro", "atezo", "ipilimumab", "CTLA-4", "CTLA", "immune checkpoint", "ICI" and "checkpoint inhibitors". Patients encountered between 01/2014 and 06/2018 were included. We performed a comprehensive chart review and recorded patient demographics, medical history, ICI characteristics and neurotoxicity data.

\section{Neurotoxicity assessment}

We defined immune-related neurotoxicity as an autoimmune disorder related to ICI exposure. Neurologic symptoms attributed to tumor progression or systemic treatment other than ICIs were excluded. Neurotoxicities were graded retrospectively on the basis of chart review according to the National Cancer Institute's Common Terminology Criteria for Adverse Events (CTCAE) version 5.0 [15]. The scale ranges from 1 to 5 . Grades 1 and 2 are considered low-grade and grades 3 and 4 as high-grade neurotoxicity. Grade 5 describes death related to the adverse event.

\section{Statistical analysis}

Descriptive statistics were calculated for all patient data. Categorical variables are reported in absolute numbers and relative frequencies. Continuous variables are described by medians and ranges are given. Baseline patient characteristics were compared using Fisher's exact test for dichotomous categorical variables and the Wilcoxon rank sum test for continuous variables. For survival analysis, patients were followed until death or database closure. Patients alive at last follow-up were censored. Overall survival (OS) was defined as the time from ICI initiation to the date of death of any cause or last follow-up. Survival estimates and prognostic markers of outcome were calculated using the Kaplan-Meier method and log-rank test. $p$-values $<0.05$ were considered significant for all tests. All analyses were performed with the IBM SPSS Statistics software, version 25 [16].

\section{Results}

\section{Study cohort}

We identified 18 patients with ICI-mediated neurotoxicities at our institution (Table 1). Among those, one case (patient 3 in Table 2) had already been reported previously [17]. Four of 18 patients (22\%) developed low-grade neurotoxicity (grade 1-2), whereas high-grade neurotoxicity (grade 3-4) developed in 14 (78\%) patients. Most neurotoxicities were associated with ipilimumab (anti-CTLA-4) and nivolumab (anti-PD-1) therapy in combination or sequentially $(n=7$; $39 \%$ ), followed by anti-PD-1/PD-L1 (pembrolizumab, nivolumab, atezolizumab) and anti-CTLA-4 (ipilimumab) monotherapy. The most common underlying malignancy was melanoma $(n=10 ; 56 \%)$. Patients were further treated for small cell lung cancer (SCLC), non-small cell lung cancer (NSCLC) and Merkel-cell carcinoma. All patients had advanced stage disease with brain metastases present in 5 out of 18 (28\%) patients. Eight patients (44\%) of the study cohort had received prior therapy such as radiation, surgery or systemic therapies for the underlying malignancy. Patients with local tumor resection outside the nervous system were not listed. Neurological autoimmune disorders (AID) were preexistent in three patients (17\%). All of them developed high-grade neurotoxicity, including generalized myasthenia gravis (MG), ocular MG and multiple sclerosis (MS). We found no significant differences while comparing the toxicity groups (grade 1-2 versus grade 3-4) with patient demographics, cancer type, CNS metastasis, previous therapies, preexistent neurological AID or ICI regimen, albeit the frequency of these factors was low in our cohort.

\section{Neurotoxicity phenotypes}

Neurotoxicities affected the CNS, PNS and neuroendocrine system (Fig. 1). The median time from ICI administration to onset of neurotoxicities was 5 weeks (range 1-72) and the median number of ICI cycles received was 2 (range 1-36). Patients 5, 7 and 8 who developed neurotoxicities at least 6 months after ICI initiation (see Table 2) had intermittent study drug discontinuation due to non-neurologic irAEs or changed from monotherapy to combination therapy. CNS toxicities predominated and included central demyelinating disorder $(n=5 ; 28 \%)$, autoimmune encephalitis predominantly affecting the grey matter (AEGM, $n=3 ; 17 \%$ ) and aseptic meningitis ( $n=1 ; 6 \%)$ (Fig. 1a). Among them, 
Table 1 Baseline characteristics associated with neurotoxicity grade

\begin{tabular}{|c|c|c|c|c|}
\hline Neurotoxicity grade & Grade $1-2(n=4)$ & Grade $3-4(n=14)$ & Total $(n=18)$ & $p$ value \\
\hline Median age (range), years & $62.5(58-66)$ & $63(46-79)$ & $63(46-79)$ & 0.789 \\
\hline Sex, male, $n(\%)$ & $2(50)$ & $8(57)$ & $10(56)$ & 1.0 \\
\hline PD- 1 and CTLA- $4, n(\%)$ & & & & 1.0 \\
\hline Nivolumab + Ipilimumab & $2(50)$ & $5(36)$ & 7 (39) & \\
\hline PD-1/PD-L1, $n(\%)$ & & & & 0.588 \\
\hline Pembrolizumab & 0 & $4(29)$ & $4(22)$ & \\
\hline Nivolumab & $1(25)$ & $2(14)$ & $3(17)$ & \\
\hline Atezolizumab & 0 & $1(7)$ & $1(6)$ & \\
\hline CTLA-4, $n(\%)$ & & & & 1.0 \\
\hline Ipilimumab & $1(25)$ & $2(14)$ & $3(17)$ & \\
\hline \multicolumn{5}{|l|}{ Cancer type, $n(\%)$} \\
\hline Melanoma & $3(75)$ & $7(50)$ & $10(56)$ & 0.588 \\
\hline SCLC & $1(25)$ & $3(21)$ & $4(22)$ & 1.0 \\
\hline NSCLC & 0 & $3(21)$ & $3(17)$ & 1.0 \\
\hline Merkel-cell carcinoma & 0 & $1(7)$ & $1(6)$ & 1.0 \\
\hline CNS metastasis ${ }^{\mathrm{a}}, n(\%)$ & $1(25)$ & $4(29)$ & $5(28)$ & 1.0 \\
\hline \multicolumn{5}{|l|}{ Prior therapy, $n(\%)$} \\
\hline CNS radiosurgery/surgical resection & 0 & $2(14)$ & $2(11)$ & 1.0 \\
\hline Systemic therapy ${ }^{\mathrm{b}}$ & $1(25)$ & $4(29)$ & $5(28)$ & 1.0 \\
\hline Two or more & 0 & $1(7)$ & $1(6)$ & 1.0 \\
\hline None & $3(75)$ & $7(50)$ & $10(56)$ & 0.588 \\
\hline Neurological AID ${ }^{\mathrm{c}}, n(\%)$ & 0 & $3(21)$ & $3(17)$ & 1.0 \\
\hline
\end{tabular}

Baseline characteristics of our cohort stratified by neurotoxicity. $p$ values are given for Fisher's exact and Wilcoxon rank sum tests

AID autoimmune disorder, CNS central nervous system, ICI immune checkpoint inhibitor, NSCLC nonsmall cell lung cancer, $S C L C$ small cell lung cancer

${ }^{a}$ Presence of CNS metastasis before ICI therapy

${ }^{\mathrm{b}}$ Systemic therapy included chemotherapy or molecular targeted therapy

${ }^{c}$ History of neurological AID before ICI therapy included generalized and ocular MG and MS seven were high-grade toxicities (Fig. 1b). PNS toxicities $(n=6 ; 33 \%)$ included MG $(n=3 ; 17 \%)$, MG complicated by myositis and myocarditis $(n=1 ; 6 \%)$ and sensorimotor polyneuropathy $(n=2 ; 11 \%)$, of which all were high-grade toxicities. Neuroendocrine toxicity comprised hypophysitis $(n=3,17 \%)$, with one case of high-grade severity. Concurrent non-neurologic irAEs were observed in 15 patients (83\%), presenting as fatigue $(n=8)$, fever $(n=2)$, skin rash $(n=4)$, vitiligo $(n=2)$, sicca-syndrome $(n=1)$, transaminitis $(n=4)$, diabetes mellitus type 1 (DM1; $n=1)$, adrenalitis $(n=1)$, hypothyroidism $(n=2)$, colitis $(n=1)$, pancreatitis $(n=1)$ and arthralgia $(n=3)$. Table 2 summarizes characteristics, diagnostic evaluations, management and outcome of ICI-related neurotoxicity in our cohort.

\section{Central demyelinating disorder $(n=5)$}

Central demyelinating disorder was diagnosed in patients $1-5$. Onset occurred at a median of 15 weeks (range 3-36). Patient 1, with preexistent relapsing-remitting MS, experienced a flare following atezolizumab. Patients 2-5 developed new onset demyelinating disorders. Patient 2 had optic neuritis, manifesting as bilateral vision loss. Patient 3 with acute demyelinating encephalomyelitis (ADEM), presented with subacute encephalopathy. Patient 4, diagnosed with a demyelinating overlap syndrome, developed dysesthesias in the extremities and proximal muscle weakness. Patient 5 had a focal demyelinating encephalitis, presenting with leg heaviness. MRI abnormalities consistent with demyelinating lesions were present in four of five patients. Patients 3 and 5 required histopathologic confirmation due to the close proximity of new demyelinating lesions to previous gamma knife radiosurgery (GKRS) sites.

\section{Autoimmune encephalitis predominantly affecting the grey matter $(n=3)$}

AEGM developed in patients $6-8$ with metastatic lung cancer and diagnosis was supported by a combination of serology, MRI, cerebral spinal fluid (CSF) and EEG findings. 


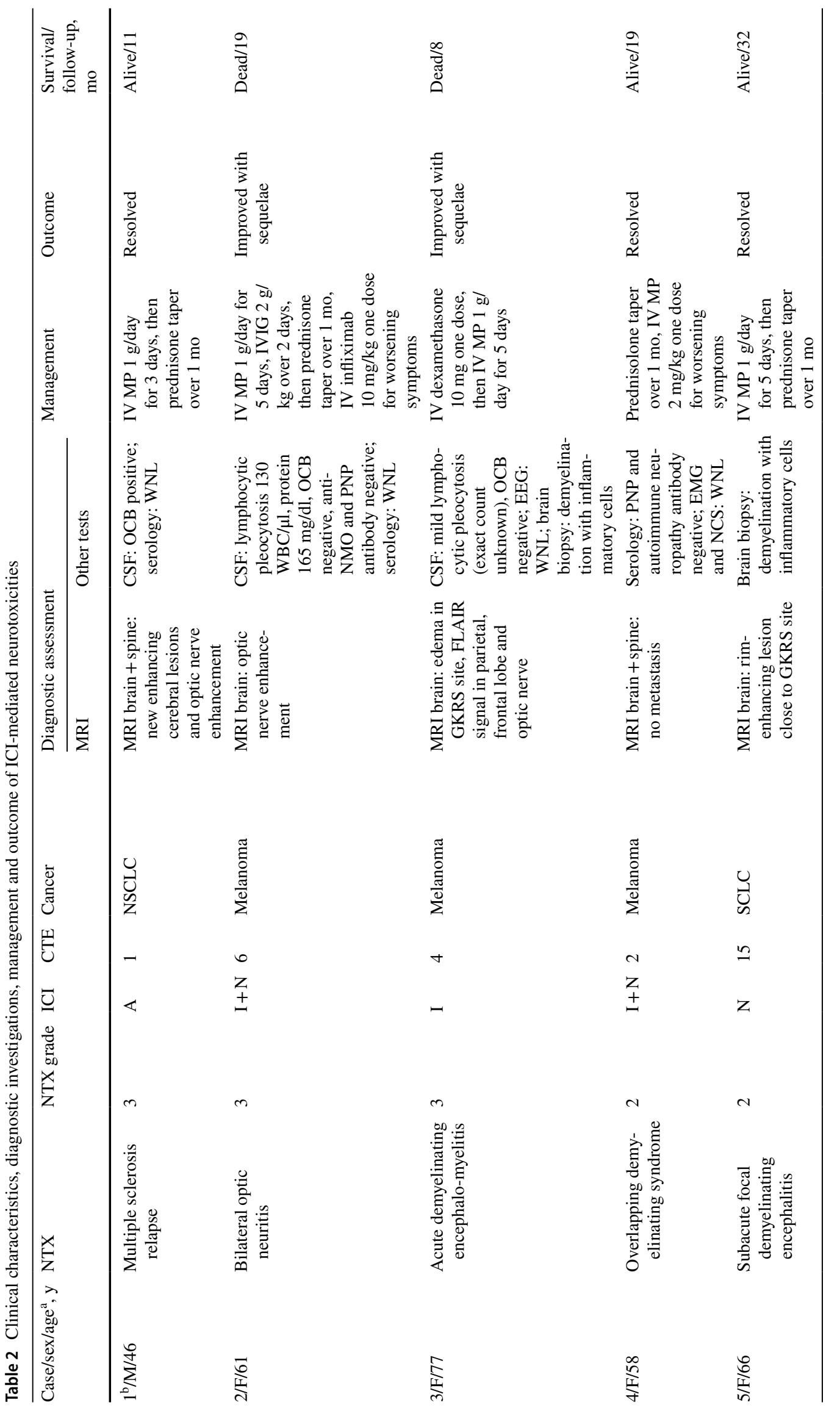




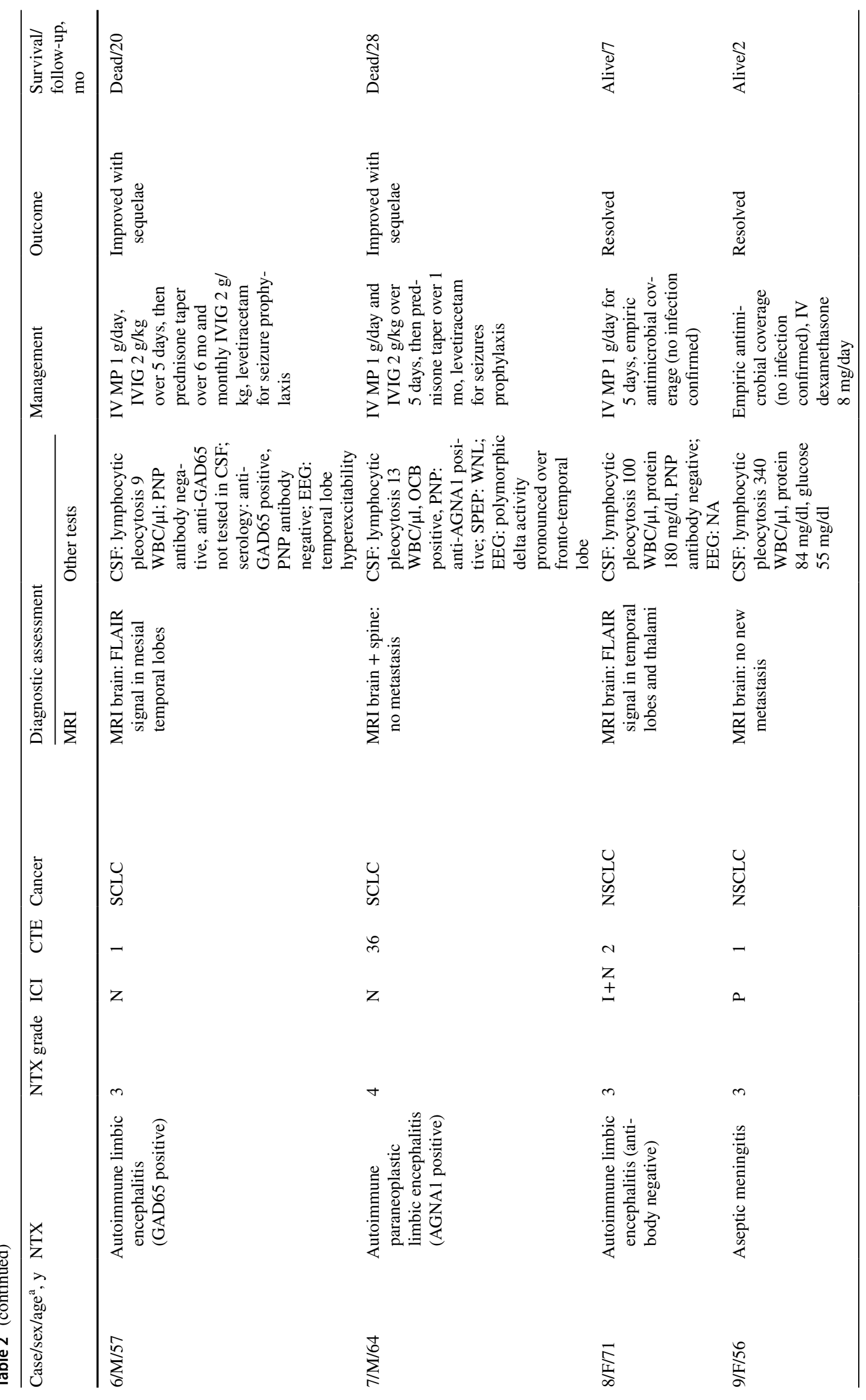




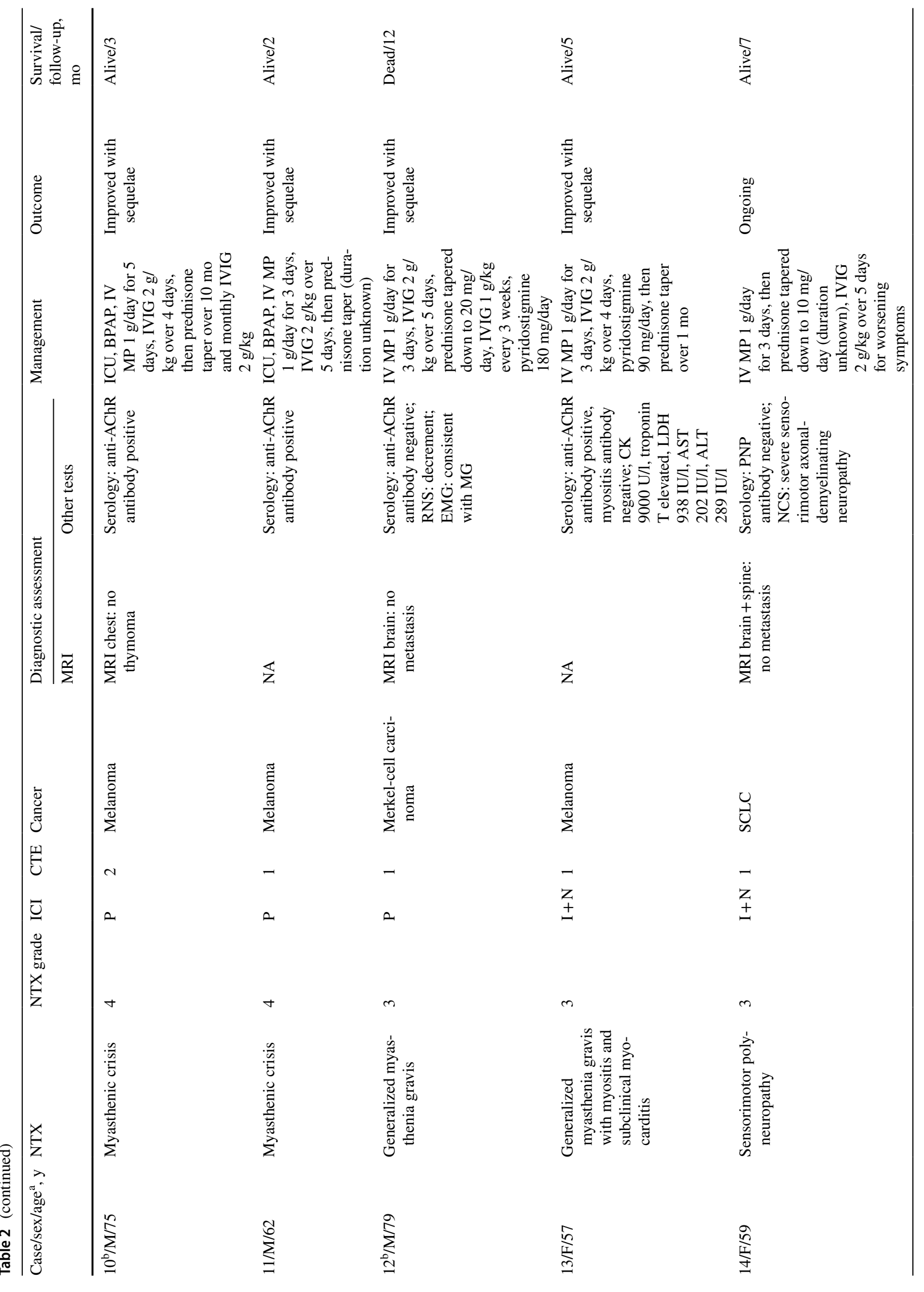




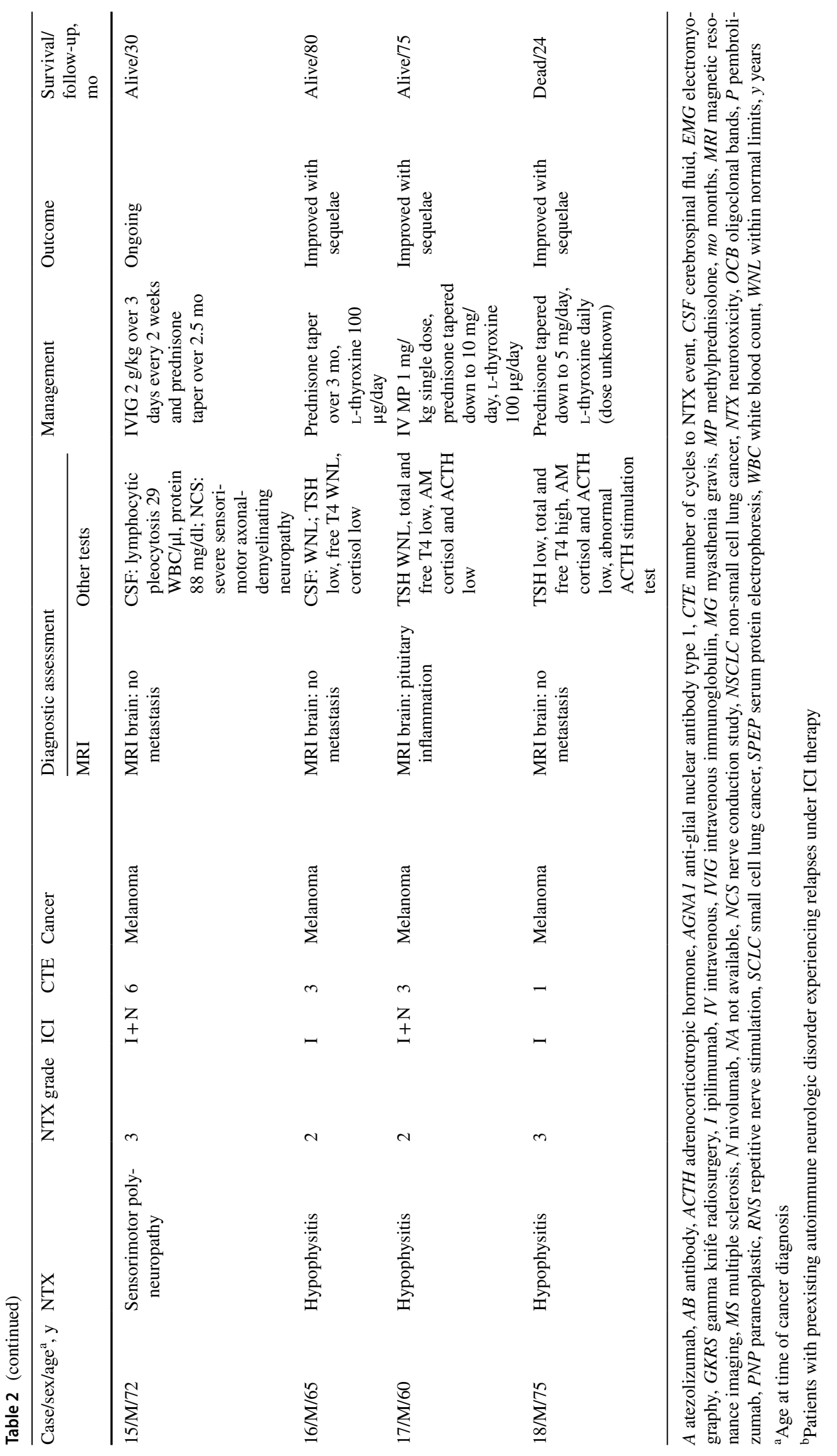




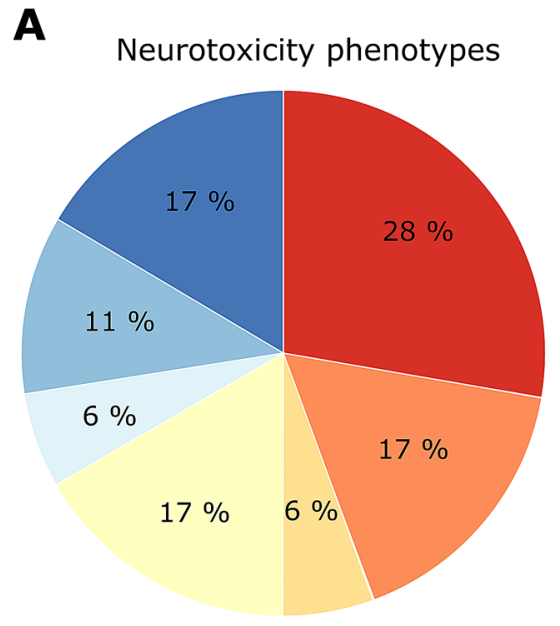

Fig. 1 Characteristics of neurotoxicity (NTX). (a) Pie chart depicting the different phenotypes of NTX associated with ICIs $(n=18)$. Central demyelinating disorders were the most frequent neurotoxicities $(n=5 ; 28 \%)$. (b) Stacked bar chart showing number of patients with

Time to symptom onset was at 5,24 and 72 weeks after ICI initiation. All patients presented with subacute encephalopathy. Limbic system involvement was suggested by psychiatric symptoms. Patient 6 with glutamic acid decarboxylase 65 antibody (GAD65) positive autoimmune limbic encephalitis, also developed new-onset insulin dependent DM1 following 1 cycle of ICI. Patient 7 was diagnosed with anti-glial nuclear antibody type 1 (AGNA1) positive limbic encephalitis. Patient 8 had antibody negative autoimmune limbic encephalitis.

\section{Aseptic meningitis $(n=1)$}

Patient 9 developed aseptic meningitis 3 weeks following pembrolizumab therapy and presented with fever and headache.

\section{Myasthenia gravis $(n=3)$ and myasthenia gravis with concurrent myositis $(n=1)$}

High-grade MG was diagnosed in patients $10-13$ and presented with a median time to onset of 13 days (range 4-29). Patients 10 and 11 had life-threatening myasthenic crisis with respiratory failure. Notably, patient 10 had preexistent anti-AChR-antibody positive generalized MG, stably controlled on immunosuppression. Patient 12, with a previous episode of ocular myasthenia, developed generalized MG. Patient 13, with a family history of MG, developed generalized MG with concurrent myositis. Clinically, the patient presented with diplopia, ptosis, muscle weakness with fatigability and myalgia. Laboratory work-up demonstrated elevated creatine kinase, lactate dehydrogenase,
Neurotoxicity and severity grade

Central demyelinating disorder AEGM

Aseptic meningitis Myasthenia gravis

Myasthenia gravis with myositis Sensorimotor polyneuropathy Hypophysitis
NTX phenotypes and their respective severity grade. High-grade neurotoxicities $(n=14 ; 78 \%)$ were more common than low-grade NTX $(n=4 ; 22 \%)$. Note that the legend applies to both panels. AEGM autoimmune encephalitis predominantly affecting the grey matter

liver transaminases and cardiac troponin T. Concomitant immune-mediated subclinical myocarditis was suspected as ECG and echocardiogram were negative for any acute pathology or structural damage. Serologic tests revealed anti-AChR antibodies in three out of four patients (patients 10,11 and 13).

\section{Sensorimotor axonal-demyelinating polyneuropathy $(n=2)$}

Patients 14 and 15 were diagnosed with sensorimotor axonal-demyelinating polyneuropathy, based on clinical and electrodiagnostic evaluation, following 3 and 12 weeks of combined nivolumab and ipilimumab therapy, respectively. Although previous treatment with carboplatin and cisplatin was reported in patient 14 , the onset of neurotoxicity immediately after ICI initiation supported an immune-related pathogenesis.

\section{Hypophysitis $(n=3)$}

Hypophysitis developed in patients $16-18$ with metastatic melanoma within 4-7 weeks of ICI therapy. Symptoms included fatigue, headaches, insomnia, confusion and proximal muscle weakness. Diagnosis of hypophysitis induced hypopituitarism was established by low serum levels of pituitary hormones, while patient 17 also had MRI findings consistent with pituitary inflammation.

\section{Clinical outcome and prognostic factors}

In all cases, ICIs were held and corticosteroids started. Corticosteroids were commonly administered as pulse-dose IV 
methylprednisolone (Table 2), followed by a slow prednisone taper over at least 4 weeks. Additional immunosuppression with intravenous immunoglobulins (IVIG) was administered in 9 out of 18 patients (50\%) and patient 2 also received infliximab. Six out of the cohort (33\%) continued maintenance therapy: patients 10,12 and 13 with MG received IVIG or pyridostigmine and patients 16-18 remained on long-term hormone substitution for hypopituitarism. Sixteen out of 18 patients (89\%) were responsive to immunosuppressive therapy with complete resolution of neurotoxicity in five patients (28\%) (Fig. 2a).

Anti-PD-1 monotherapy was resumed in two patients (4 and 17), both with low-grade neurotoxicity and prompt improvement following immunosuppression. No neurologic and non-neurologic irAEs developed with resumption of anti-PD-1 monotherapy. However, patient 4 with subsequent anti-PD-1/CTLA-4 combination therapy experienced grade 4 transaminitis, leading to permanent ICI discontinuation. At the time of database closure, 12 patients were alive
(67\%) and $6(33 \%)$ had died, all of whom were among the high-grade neurotoxicity group. The fatalities were due to progression of the underlying cancer. Median follow-up was 19 months (range 2-80). The median OS for the cohort was not reached, as more than half of the patients were still alive at the end of follow-up (Fig. 2b). High-grade neurotoxicity $(n=14)$ was a significant negative prognostic factor for OS $(p=0.046)$ when compared to patients with low-grade neurotoxicity $(n=4)$ (Fig. 2c). OS did not significantly differ between CNS and non-CNS toxicity ( $p=0.202)$ (Fig. 2d).

\section{Discussion}

While ICIs have revolutionized the field of cancer immunotherapy [18], they can be complicated by serious neurotoxicities $[1,9,19,20]$, and clinical experience with the toxic potential of ICIs is still limited. Thus, a comprehensive definition of the diverse set of neurotoxicities

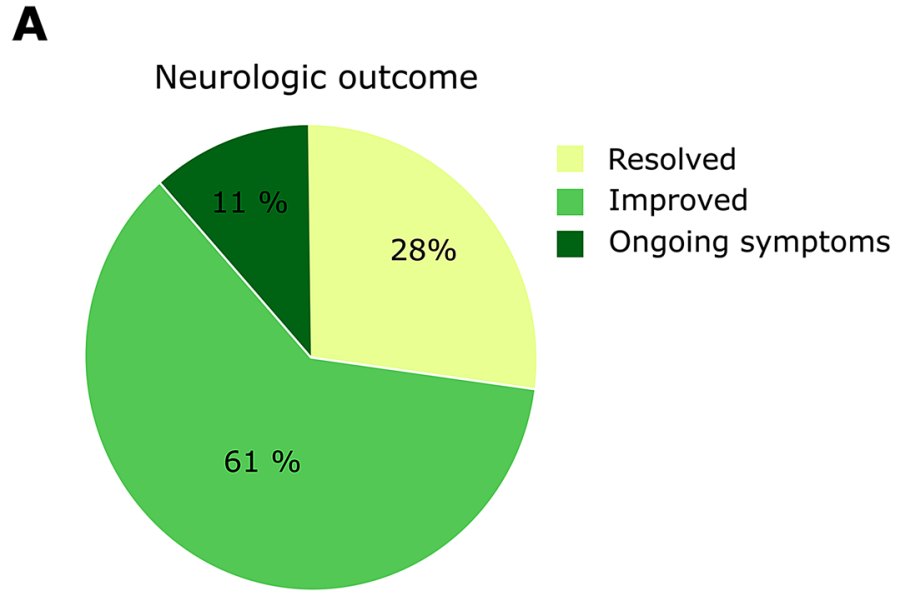

B
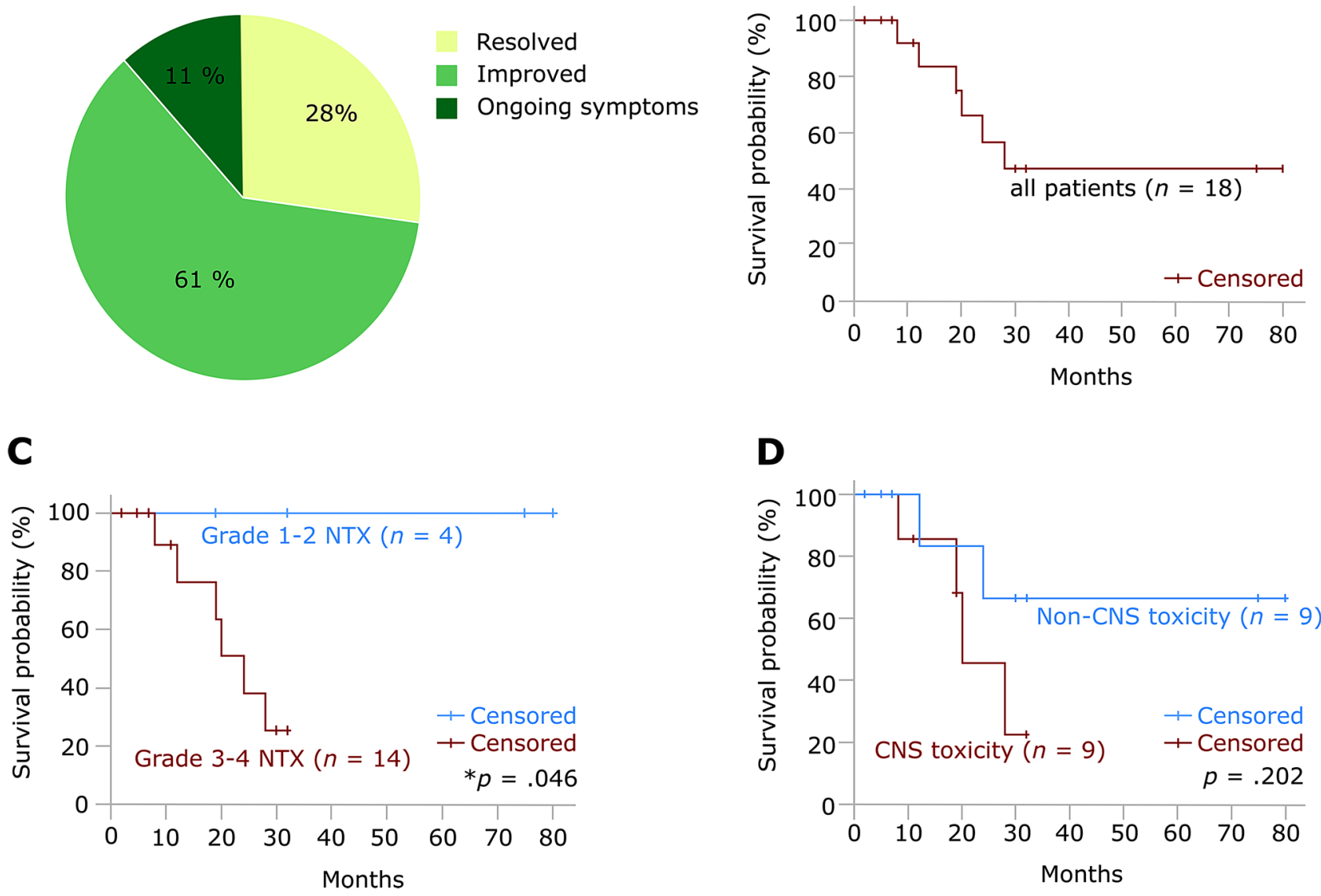

Fig. 2 Neurologic outcome and prognostic marker for OS in patients with neurotoxicity (NTX). (a) Pie chart depicting the neurologic outcome following immunosuppressive management of NTX $(n=18)$.

(b) Kaplan-Meier estimates of OS in this study cohort $(n=18)$. (c) OS curves stratified by grade of neurotoxicity. (d) OS curves comparing CNS and non-CNS toxicity. Tick marks indicate censored patients 
is required to increase awareness among clinicians and facilitate management for a favorable patient outcome. To the best of our knowledge, we present one of the largest single-center case series to date with long-term follow-up of ICI-related neurotoxicities. Contrary to previously published studies, our cohort comprised patients with various types of cancers undergoing different ICI regimens, thus reducing selection bias in this study.

We observed highly variable neurotoxic phenotypes. Clinical presentation can be non-specific including headaches or fatigue, leading to a lack of recognition of these events as ICI-related neurotoxicities [21]. While neurotoxicities have mostly been reported to involve the PNS $[7,22]$, inflammatory CNS disorders were predominant in our series. Inflammatory CNS disorders are rare complications with a reported incidence from $0.4 \%$ to $1.0 \%$ [23], yet more studies report ICI-mediated demyelinating diseases, autoimmune encephalitis predominantly affecting the grey matter and aseptic meningitis [24-26].

Central demyelinating diseases associated with ICIs can occur de novo or present as an exacerbation of a preexisting condition and have to be distinguished from brain metastasis or radiation necrosis. In prior recipients of GKRS, distinction of ICI-induced demyelination, radiation necrosis, or relapsed tumor may be difficult [27] and require histopathologic confirmation as seen in our cohort. Such cases with demyelination in close proximity to previously irradiated areas raise the question whether radiosurgery increases susceptibility to ICI-associated CNS toxicity. Several studies have demonstrated that radiationinduced disruption of the blood brain barrier facilitates exposure of neural antigens to peripheral immune cells, promoting humoral autoimmunity [11, 28, 29]. Further investigation is required to explore the interplay of radiosurgery and ICIs in the development of CNS inflammation.

ICI-mediated autoimmune encephalitis has to be distinguished from classic paraneoplastic neurologic disorders (PND). Certain characteristics more indicative of an ICImediated etiology have been observed in our cohort and include: (1) the development of autoimmune encephalitis late in the course of cancer whereas classic PNDs usually precede cancer diagnosis, (2) the onset of neurotoxicity following ICI exposure, demonstrating timely association with the agent, and (3) the responsiveness to immunosuppression whereas tumor-induced PNDs are commonly refractory to these measures, but may improve with cancer therapy [30]. On the other side, the observation of a positive classic paraneoplastic AGNA-1 antibody shortly after ICI initiation suggests that ICIs may be able to unmask paraneoplastic encephalitis, indicating that these etiologies are not mutually exclusive.

ICI-mediated aseptic meningitis has been previously described in the literature and in accordance with our observations, the neurotoxicity is highly responsive to steroids [9].

Myasthenia gravis has been increasingly recognized as a severe neurotoxicity with a mortality rate estimated at $30.4 \%$ [8]. For most ICI-related cases, prognosis is poor with rapid clinical deterioration, increased risk for life-threatening myasthenic crisis and concurrent myositis compared to classic MG $[31,32]$.

Acute sensorimotor neuropathy and hypophysitis are both more frequently encountered ICI-mediated neurotoxicities $[22,33]$. These phenotypes are likely underrepresented in our cohort as we may not have been consulted on cases with mild and transient peripheral neuropathy $[13,25]$ or hypophysitis.

Time to onset of neurotoxicities varied greatly with a tendency for early presentation within a few weeks after ICI administration. Whether the timing of neurotoxicities depends on a specific phenotype or is associated with treatment-specific or patient-specific factors remains unclear.

Diagnosis of ICI-mediated neurotoxicities poses a great challenge as the differential diagnosis is broad, ranging from tumor progression, PND, metabolic derangements, infections and complications related to concurrent treatment modalities. Our study highlights the pivotal role of MRI in the evaluation of CNS toxicities. Meningeal enhancement, pituitary inflammation or demyelination may aid in the early diagnosis of ICI-related aseptic meningitis, hypophysitis and central demyelinating disorders, respectively.

The majority of our patients showed a favorable neurologic outcome following ICI discontinuation and steroid therapy, further providing evidence supporting the current guidelines for management of irAEs [34]. Depending on the severity of the neurotoxicity, further immunomodulation with IVIG, plasmapheresis or immunosuppressive drugs might be required [34]. Based on our observations, in patients with neurotoxicities higher than grade 1 the threshold to withhold ICIs and commence steroids or more aggressive immunosuppression should be low in order to prevent permanent damage to the nervous system [32]. It has been encouraging that a correlation between systemic steroid use and a negative impact on the anticancer effect of ICI therapy has not been clearly established $[35,36]$.

Data regarding the use of ICIs in patients with preexisting autoimmune neurologic conditions are limited as most clinical trials have excluded patients with known AID. Our data suggest that preexistent AID may increase the risk for highgrade toxicities. However, since most of the neurotoxicities can be successfully managed [7, 37], autoimmunity should not be an absolute contraindication for the life-prolonging effect of ICIs.

We identified high-grade neurotoxicity as a negative prognostic factor for OS. Although mortalities occurred late in the course of ICI therapy (median of 19.5 months, 
range 8.0-28.0), and cause of death was the progression of the underlying malignancy, neurotoxicities may have negatively impacted OS based on the following explanations: First, high-grade neurotoxicities impose greater damage to the nervous system with the potential of progressing to a life-threatening condition. Second, the aggressive immunosuppression to control for these neurotoxicities raises the risk for opportunistic infections and metabolic derangements that again increases morbidity. Third, high-grade neurotoxicities may be too severe for ICI resumption allowing for uncontrolled tumor progression. As ICIs have demonstrated improved OS rates $[1,19,38]$, the impact of ICI discontinuation due to neurotoxicities on OS is deleterious. Optimized patient support is warranted to overcome these neurotoxicities in order to resume ICIs for adequate cancer management.

\section{Limitations}

Despite the comparatively abundant patient data presented in this study, some limitations arise. Retrospective study designs are prone to selection bias. Our colleagues may have consulted us preferentially for neurotoxicities of higher grade and complexity, while low-grade or previously described neurotoxicities (hypophysitis, demyelinating polyneuropathy) might be underrepresented. While previous reports have listed non-specific presentations (headaches, dysgeusia or insomnia) as neurologic irAEs, we did not include these symptoms as a separate neurotoxicity as they are non-specific and can occur in a variety of non-neurologic disorders. Despite having a standardized grading system for irAEs, toxicity grading is subject to interobserver variability. The short follow-up period limits meaningful survival analyses, as neurotoxicities may develop over time, even after discontinuation of ICIs. The number of cases in our cohort restricts its statistical power and does not allow for firm conclusions for all studied dependencies.

\section{Conclusion}

ICIs are emerging as powerful cancer immunotherapies but are associated with a broad spectrum of early onset, rapidly progressing and potentially fatal neurotoxicities. Considering the expanding indications for ICIs, neurotoxicities are anticipated to become more prevalent. Therefore, physicians need to be familiar with these irAEs as timely management is crucial to reduce morbidity and mortality. Neurotoxicities need to be distinguished from complications of the underlying malignancy, metabolic derangements, or complications of other therapies. Overall, most ICI-mediated neurotoxicities are responsive to steroid therapy. Randomized prospective studies for diagnostic and treatment algorithms are needed to improve patient outcomes and develop predictive biomarkers for identifying patients at risk for neurotoxicities.

Acknowledgements The abstract was previously presented at the American Academy of Neurology 2019 Annual Meeting in Philadelphia, PA, United States of America and the American Neurology Association Meeting 2018 in Atlanta, GA, United States of America.

Authors contributions SLD, FJB and JMB designed the study, analyzed, interpreted the data, and drafted the manuscript. SLD, FJB, JMB and RJN acquired patient records. All authors critically revised, read and approved the final manuscript.

Funding No funding was received for conducting this study.

Data availability Data available on request from the authors.

\section{Compliance with ethical standards}

Conflict of interest The authors have no conflicts of interest to declare that are relevant to the content of this article.

Ethical approval Study design and methods were approved by the institutional review board of Yale School of Medicine.

\section{References}

1. Larkin J, Chiarion-Sileni V, Gonzalez R, Grob JJ, Cowey CL, Lao CD, Schadendorf D, Dummer R, Smylie M, Rutkowski P, Ferrucci PF, Hill A, Wagstaff J, Carlino MS, Haanen JB, Maio M, Marquez-Rodas I, McArthur GA, Ascierto PA, Long GV, Callahan MK, Postow MA, Grossmann K, Sznol M, Dreno B, Bastholt L, Yang A, Rollin LM, Horak C, Hodi FS, Wolchok JD (2015) Combined nivolumab and ipilimumab or monotherapy in untreated melanoma. N Engl J Med 373(1):23-34. https://doi. org/10.1056/NEJMoa1504030

2. Reck M, Rodríguez-Abreu D, Robinson AG, Hui R, Csőszi T, Fülöp A, Gottfried M, Peled N, Tafreshi A, Cuffe S, O'Brien M, Rao S, Hotta K, Leiby MA, Lubiniecki GM, Shentu Y, Rangwala R, Brahmer JR (2016) Pembrolizumab versus chemotherapy for PD-L1-positive non-small-cell lung cancer. N Engl J Med 375(19):1823-1833. https://doi.org/10.1056/NEJMoa1606774

3. Motzer RJ, Escudier B, McDermott DF, George S, Hammers HJ, Srinivas S, Tykodi SS, Sosman JA, Procopio G, Plimack ER, Castellano D, Choueiri TK, Gurney H, Donskov F, Bono P, Wagstaff J, Gauler TC, Ueda T, Tomita Y, Schutz FA, Kollmannsberger C, Larkin J, Ravaud A, Simon JS, Xu L-A, Waxman IM, Sharma P (2015) Nivolumab versus everolimus in advanced renal-cell carcinoma. N Engl J Med 373(19):1803-1813. https://doi.org/10.1056/ NEJMoa1510665

4. Tang J, Yu JX, Hubbard-Lucey VM, Neftelinov ST, Hodge JP, Lin Y (2018) Trial watch: The clinical trial landscape for PD1/PDL1 immune checkpoint inhibitors. Nat Rev Drug Discov 17(12):854855. https://doi.org/10.1038/nrd.2018.210

5. Pardoll DM (2012) The blockade of immune checkpoints in cancer immunotherapy. Nat Rev Cancer 12(4):252-264. https://doi. org $/ 10.1038 / \mathrm{nrc} 3239$ 
6. Postow MA, Sidlow R, Hellmann MD (2018) Immune-related adverse events associated with immune checkpoint blockade. $\mathrm{N}$ Engl J Med 378(2):158-168. https://doi.org/10.1056/NEJMra1703 481

7. Cuzzubbo S, Javeri F, Tissier M, Roumi A, Barlog C, Doridam J, Lebbe C, Belin C, Ursu R, Carpentier AF (2017) Neurological adverse events associated with immune checkpoint inhibitors: review of the literature. Eur J Cancer 73:1-8. https://doi. org/10.1016/j.ejca.2016.12.001

8. Makarious D, Horwood K, Coward JIG (2017) Myasthenia gravis: an emerging toxicity of immune checkpoint inhibitors. Eur J Cancer 82:128-136. https://doi.org/10.1016/j.ejca.2017.05.041

9. Touat M, Talmasov D, Ricard D, Psimaras D (2017) Neurological toxicities associated with immune-checkpoint inhibitors. Curr Opin Neurol 30(6):659-668. https://doi.org/10.1097/wco.00000 00000000503

10. Barroso-Sousa R, Barry WT, Garrido-Castro AC, Hodi FS, Min L, Krop IE, Tolaney SM (2018) Incidence of endocrine dysfunction following the use of different immune checkpoint inhibitor regimens: a systematic review and meta-analysis. JAMA Oncol 4(2):173-182. https://doi.org/10.1001/jamaoncol.2017.3064

11. Williams TJ, Benavides DR, Patrice KA, Dalmau JO, de Avila AL, Le DT, Lipson EJ, Probasco JC, Mowry EM (2016) Association of autoimmune encephalitis with combined immune checkpoint inhibitor treatment for metastatic cancer. JAMA Neurol 73(8):928-933. https://doi.org/10.1001/jamaneurol.2016.1399

12. Fellner A, Makranz C, Lotem M, Bokstein F, Taliansky A, Rosenberg S, Blumenthal DT, Mandel J, Fichman S, Kogan E, Steiner I, Siegal T, Lossos A, Yust-Katz S (2018) Neurologic complications of immune checkpoint inhibitors. J Neuro-Oncol 137(3):601-609. https://doi.org/10.1007/s11060-018-2752-5

13. Spain L, Walls G, Julve M, O’Meara K, Schmid T, Kalaitzaki E, Turajlic S, Gore M, Rees J, Larkin J (2017) Neurotoxicity from immune-checkpoint inhibition in the treatment of melanoma: a single centre experience and review of the literature. Ann Oncol 28(2):377-385. https://doi.org/10.1093/annonc/mdw558

14. Kao JC, Liao B, Markovic SN, Klein CJ, Naddaf E, Staff NP, Liewluck T, Hammack JE, Sandroni P, Finnes H, Mauermann ML (2017) Neurological complications associated with anti-programmed death 1 (PD-1) antibodies. JAMA Neurol 74(10):12161222. https://doi.org/10.1001/jamaneurol.2017.1912

15. National Cancer Institute (2017) CTCAE v5.0 Quick Reference 8.5x11. https://ctep.cancer.gov/protocolDevelopment/electronic _applications/docs/CTCAE_v5_Quick_Reference_8.5x11.pdf. Accessed 20 Mar 2019

16. IBM Corp (2017) IBM SPSS statistics for Macintosh, Version 25.0. IBM Corp., Armonk, NY

17. Cao Y, Nylander A, Ramanan S, Goods BA, Ponath G, Zabad R, Chiang VL, Vortmeyer AO, Hafler DA, Pitt D (2016) CNS demyelination and enhanced myelin-reactive responses after ipilimumab treatment. Neurology 86(16):1553-1556. https://doi. org/10.1212/wnl.0000000000002594

18. Ribas A, Wolchok JD (2018) Cancer immunotherapy using checkpoint blockade. Science 359(6382):1350-1355. https://doi. org/10.1126/science.aar4060

19. Wolchok JD, Chiarion-Sileni V, Gonzalez R, Rutkowski P, Grob JJ, Cowey CL, Lao CD, Wagstaff J, Schadendorf D, Ferrucci PF, Smylie M, Dummer R, Hill A, Hogg D, Haanen J, Carlino MS, Bechter O, Maio M, Marquez-Rodas I, Guidoboni M, McArthur G, Lebbe C, Ascierto PA, Long GV, Cebon J, Sosman J, Postow MA, Callahan MK, Walker D, Rollin L, Bhore R, Hodi FS, Larkin J (2017) Overall survival with combined nivolumab and ipilimumab in advanced melanoma. N Engl J Med 377(14):13451356. https://doi.org/10.1056/NEJMoa1709684

20. Weber JS, D'Angelo SP, Minor D, Hodi FS, Gutzmer R, Neyns B, Hoeller C, Khushalani NI, Miller WH, Lao CD, Linette GP,
Thomas L, Lorigan P, Grossmann KF, Hassel JC, Maio M, Sznol M, Ascierto PA, Mohr P, Chmielowski B, Bryce A, Svane IM, Grob J-J, Krackhardt AM, Horak C, Lambert A, Yang AS, Larkin J (2015) Nivolumab versus chemotherapy in patients with advanced melanoma who progressed after anti-CTLA-4 treatment (CheckMate 037): a randomised, controlled, openlabel, phase 3 trial. Lancet Oncol 16(4):375-384. https://doi. org/10.1016/S1470-2045(15)70076-8

21. Hottinger AF (2016) Neurologic complications of immune checkpoint inhibitors. Curr Opin Neurol 29(6):806-812. https ://doi.org/10.1097/wco.0000000000000391

22. Dubey D, David WS, Amato AA, Reynolds KL, Clement NF, Chute DF, Cohen JV, Lawrence DP, Mooradian MJ, Sullivan RJ, Guidon AC (2019) Varied phenotypes and management of immune checkpoint inhibitor-associated neuropathies. Neurology 93(11):e1093-e1103. https://doi.org/10.1212/wnl.00000 00000008091

23. Blackmon JT, Viator TM, Conry RM (2016) Central nervous system toxicities of anti-cancer immune checkpoint blockade. J Neurol Neuromed 1(4):39-45

24. Maurice C, Schneider R, Kiehl T-R, Bavi P, Roehrl MHA, Mason WP, Hogg D (2015) Subacute CNS demyelination after treatment with nivolumab for melanoma. Cancer Immunol Res. https://doi.org/10.1158/2326-6066.Cir-15-0141

25. Larkin J, Chmielowski B, Lao CD, Hodi FS, Sharfman W, Weber J, Suijkerbuijk KPM, Azevedo S, Li H, Reshef D, Avila A, Reardon DA (2017) Neurologic serious adverse events associated with nivolumab plus ipilimumab or nivolumab alone in advanced melanoma, including a case series of encephalitis. Oncologist 22(6):709-718. https://doi.org/10.1634/theoncolog ist.2016-0487

26. Garcia CA, El-Ali A, Rath TJ, Contis LC, Gorantla V, Drappatz J, Davar D (2018) Neurologic immune-related adverse events associated with adjuvant ipilimumab: report of two cases. J Immunother Cancer 6(1):83. https://doi.org/10.1186/s40425-018-0393-z

27. Alomari A, Rauch PJ, Orsaria M, Minja FJ, Chiang VL, Vortmeyer AO (2014) Radiologic and histologic consequences of radiosurgery for brain tumors. J Neuro-Oncol 117(1):33-42. https ://doi.org/10.1007/s11060-014-1359-8

28. Hwang WL, Pike LRG, Royce TJ, Mahal BA, Loeffler JS (2018) Safety of combining radiotherapy with immune-checkpoint inhibition. Nat Rev Clin Oncol 15(8):477-494. https://doi.org/10.1038/ s41571-018-0046-7

29. Lehrer EJ, McGee HM, Peterson JL, Vallow L, Ruiz-Garcia H, Zaorsky NG, Sharma S, Trifiletti DM (2018) Stereotactic radiosurgery and immune checkpoint inhibitors in the management of brain metastases. Int J Mol Sci 19(10):3054. https://doi. org/10.3390/ijms 19103054

30. Darnell RB, Posner JB (2003) Paraneoplastic syndromes involving the nervous system. N Engl J Med 349(16):1543-1554. https:// doi.org/10.1056/NEJMra023009

31. Suzuki S, Ishikawa N, Konoeda F, Seki N, Fukushima S, Takahashi K, Uhara H, Hasegawa Y, Inomata S, Otani Y, Yokota K, Hirose T, Tanaka R, Suzuki N, Matsui M (2017) Nivolumabrelated myasthenia gravis with myositis and myocarditis in Japan. Neurology 89(11):1127-1134. https://doi.org/10.1212/wnl.00000 00000004359

32. Zimmer L, Goldinger SM, Hofmann L, Loquai C, Ugurel S, Thomas I, Schmidgen MI, Gutzmer R, Utikal JS, Göppner D, Hassel JC, Meier F, Tietze JK, Forschner A, Weishaupt C, Leverkus M, Wahl R, Dietrich U, Garbe C, Kirchberger MC, Eigentler T, Berking C, Gesierich A, Krackhardt AM, Schadendorf D, Schuler G, Dummer R, Heinzerling LM (2016) Neurological, respiratory, musculoskeletal, cardiac and ocular side-effects of anti-PD-1 therapy. Eur J Cancer 60:210-225. https://doi.org/10.1016/j. ejca.2016.02.024 
33. Gu Y, Menzies AM, Long GV, Fernando SL, Herkes G (2017) Immune mediated neuropathy following checkpoint immunotherapy. J Clin Neurosci 45:14-17. https://doi.org/10.1016/j. jocn.2017.07.014

34. Brahmer JR, Lacchetti C, Schneider BJ, Atkins MB, Brassil KJ, Caterino JM, Chau I, Ernstoff MS, Gardner JM, Ginex P, Hallmeyer S, Chakrabarty JH, Leighl NB, Mammen JS, McDermott DF, Naing A, Nastoupil LJ, Phillips T, Porter LD, Puzanov I, Reichner CA, Santomasso BD, Seigel C, Spira A, Suarez-Almazor ME, Wang Y, Weber JS, Wolchok JD, Thompson JA, Network icwtNCC (2018) Management of immune-related adverse events in patients treated with immune checkpoint inhibitor therapy: American Society of Clinical Oncology clinical practice guideline. J Clin Oncol 36(17):1714-1768. https://doi.org/10.1200/ jco.2017.77.6385

35. Horvat TZ, Adel NG, Dang TO, Momtaz P, Postow MA, Callahan MK, Carvajal RD, Dickson MA, D'Angelo SP, Woo KM, Panageas KS, Wolchok JD, Chapman PB (2015) Immune-related adverse events, need for systemic immunosuppression, and effects on survival and time to treatment failure in patients with melanoma treated with ipilimumab at Memorial Sloan Kettering Cancer Center. J Clin Oncol 33(28):3193-3198. https://doi. org/10.1200/jco.2015.60.8448

36. Abu-Sbeih H, Tang T, Ali F, Johnson D, Qiao W, Diab A, Wang Y (2018) The impact of immune checkpoint inhibitor-related adverse events and their immunosuppressive treatment on patients' outcomes. J Immunother Precis Oncol 1(1):7-18. https://doi. org/10.4103/jipo.Jipo_12_18

37. Spain L, Tippu Z, Larkin JM, Carr A, Turajlic S (2019) How we treat neurological toxicity from immune checkpoint inhibitors. ESMO Open 4(Suppl 4):e000540. https://doi.org/10.1136/esmoo pen-2019-000540

38. Ribas A, Puzanov I, Dummer R, Schadendorf D, Hamid O, Robert C, Hodi FS, Schachter J, Pavlick AC, Lewis KD, Cranmer LD, Blank CU, O’Day SJ, Ascierto PA, Salama AKS, Margolin KA, Loquai C, Eigentler TK, Gangadhar TC, Carlino MS, Agarwala SS, Moschos SJ, Sosman JA, Goldinger SM, Shapira-Frommer R, Gonzalez R, Kirkwood JM, Wolchok JD, Eggermont A, Li XN, Zhou W, Zernhelt AM, Lis J, Ebbinghaus S, Kang SP, Daud A (2015) Pembrolizumab versus investigator-choice chemotherapy for ipilimumab-refractory melanoma (KEYNOTE-002): a randomised, controlled, phase 2 trial. Lancet Oncol 16(8):908-918. https://doi.org/10.1016/S1470-2045(15)00083-2

Publisher's Note Springer Nature remains neutral with regard to jurisdictional claims in published maps and institutional affiliations. 


\section{Detailed Declaration of Contributions to the Publication}

\section{Publication:}

Duong SL, Barbiero FJ, Nowak RJ, Baehring JM. Neurotoxicities associated with immune checkpoint inhibitor therapy. J Neurooncol. 2021 Apr;152(2):265277. doi: 10.1007/s11060-021-03695-w.

The author of this thesis, Sophie L. Duong, was the main researcher in the study. Sophie L. Duong developed the working hypothesis and study design. Sophie L. Duong defined inclusion and exclusion criteria under the guidance of Prof. Joachim M. Baehring. With the assistance of Frank J. Barbiero, Dr. Richard J. Nowak, and Prof. Joachim M. Baehring, Sophie L. Duong identified patients to be included in the study. Sophie L. Duong performed a comprehensive chart review and systematically collected relevant primary patient data with support from Frank J. Barbiero. Sophie L. Duong analyzed the data and performed statistical analyses (Fisher's exact test, Wilcoxon rank sum, Kaplan-Meier method). Results were discussed with Frank J. Barbiero and Prof. Joachim M. Baehring. Sophie L. Duong designed figures and tables to visualize the study results. The manuscript was drafted by Sophie L. Duong after a comprehensive literature research and critically revised by all authors. The submission of the manuscript, as well as addressing the revisions from the peer-review process until publication in a peer-reviewed journal was executed by Sophie L. Duong under the guidance of Prof. Joachim M. Baehring. In addition, Sophie L. Duong presented the results of this study at scientific conferences (American Academy of Neurology Annual Meeting, Philadelphia, PA, USA, 2019 and American Neurological Association Annual Meeting, Atlanta, GA, USA, 2018). 


\section{References}

1. Larkin J, Chiarion-Sileni V, Gonzalez R, et al. Combined Nivolumab and Ipilimumab or Monotherapy in Untreated Melanoma. New England Journal of Medicine. 2015;373(1):23-34.

2. Wolchok JD, Chiarion-Sileni V, Gonzalez R, et al. Overall Survival with Combined Nivolumab and Ipilimumab in Advanced Melanoma. The New England journal of medicine. 2017;377(14):1345-1356.

3. Reck M, Rodríguez-Abreu D, Robinson AG, et al. Pembrolizumab versus Chemotherapy for PD-L1-Positive Non-Small-Cell Lung Cancer. New England Journal of Medicine. 2016;375(19):1823-1833.

4. Motzer RJ, Escudier B, McDermott DF, et al. Nivolumab versus Everolimus in Advanced Renal-Cell Carcinoma. New England Journal of Medicine. 2015;373(19):1803-1813.

5. Rittmeyer A, Barlesi F, Waterkamp D, et al. Atezolizumab versus docetaxel in patients with previously treated non-small-cell lung cancer (OAK): a phase 3, open-label, multicentre randomised controlled trial. The Lancet. 2017;389(10066):255-265.

6. Tang J, Yu JX, Hubbard-Lucey VM, Neftelinov ST, Hodge JP, Lin Y. Trial watch: The clinical trial landscape for PD1/PDL1 immune checkpoint inhibitors. Nature Reviews Drug Discovery. 2018;17(12):854-855.

7. Pardoll DM. The blockade of immune checkpoints in cancer immunotherapy. Nature reviews Cancer. 2012;12(4):252-264.

8. Freeman GJ, Long AJ, Iwai $Y$, et al. Engagement of the Pd-1 Immunoinhibitory Receptor by a Novel B7 Family Member Leads to Negative Regulation of Lymphocyte Activation. The Journal of Experimental Medicine. 2000;192(7):1027-1034.

9. Chambers CA, Sullivan TJ, Allison JP. Lymphoproliferation in CTLA-4Deficient Mice Is Mediated by Costimulation-Dependent Activation of CD4+ T Cells. Immunity. 1997;7(6):885-895.

10. Iwai $\mathrm{Y}$, Ishida M, Tanaka $\mathrm{Y}$, Okazaki $\mathrm{T}$, Honjo $\mathrm{T}$, Minato N. Involvement of PD-L1 on tumor cells in the escape from host immune system and tumor immunotherapy by PD-L1 blockade. Proceedings of the National Academy of Sciences. 2002;99(19):12293-12297. 
11. Carreno BM, Bennett F, Chau TA, et al. CTLA-4 (CD152) Can Inhibit T Cell Activation by Two Different Mechanisms Depending on Its Level of Cell Surface Expression. The Journal of Immunology. 2000;165(3):1352.

12. Okazaki T, Honjo T. The PD-1-PD-L pathway in immunological tolerance. Trends in Immunology. 2006;27(4):195-201.

13. Gubin MM, Zhang $X$, Schuster $\mathrm{H}$, et al. Checkpoint blockade cancer immunotherapy targets tumour-specific mutant antigens. Nature. 2014;515:577.

14. Postow MA, Sidlow R, Hellmann MD. Immune-Related Adverse Events Associated with Immune Checkpoint Blockade. The New England journal of medicine. 2018;378(2):158-168.

15. Ramos-Casals M, Brahmer JR, Callahan MK, et al. Immune-related adverse events of checkpoint inhibitors. Nature Reviews Disease Primers. 2020;6(1):38.

16. Hofmann L, Forschner A, Loquai $C$, et al. Cutaneous, gastrointestinal, hepatic, endocrine, and renal side-effects of anti-PD-1 therapy. European Journal of Cancer. 2016;60:190-209.

17. Cuzzubbo S, Javeri F, Tissier M, et al. Neurological adverse events associated with immune checkpoint inhibitors: Review of the literature. European Journal of Cancer. 2017;73:1-8.

18. Wang DY, Salem J-E, Cohen JV, et al. Fatal Toxic Effects Associated With Immune Checkpoint Inhibitors: A Systematic Review and Metaanalysis. JAMA oncology. 2018;4(12):1721-1728.

19. Brahmer JR, Lacchetti C, Schneider BJ, et al. Management of ImmuneRelated Adverse Events in Patients Treated With Immune Checkpoint Inhibitor Therapy: American Society of Clinical Oncology Clinical Practice Guideline. Journal of Clinical Oncology. 2018;36(17):1714-1768.

20. National Cancer Institute. CTCAE v5.0 Quick Reference 8.5x11. https://ctep.cancer.gov/protocolDevelopment/electronic_applications/doc s/CTCAE_v5_Quick_Reference_8.5x11.pdf. Published 2017. Accessed March 20, 2019.

21. Blackmon JT, Viator TM, Conry RM. Central nervous system toxicities of anti-cancer immune checkpoint blockade. 2016. 
22. Gerdes LA, Held K, Beltran E, et al. CTLA4 as Immunological Checkpoint in the Development of Multiple Sclerosis. Annals of Neurology. 2016;80(2):294-300.

23. Larkin J, Chmielowski B, Lao CD, et al. Neurologic Serious Adverse Events Associated with Nivolumab Plus Ipilimumab or Nivolumab Alone in Advanced Melanoma, Including a Case Series of Encephalitis. The oncologist. 2017;22(6):709-718.

24. Gettings EJ, Hackett CT, Scott TF. Severe relapse in a multiple sclerosis patient associated with ipilimumab treatment of melanoma. Multiple sclerosis (Houndmills, Basingstoke, England). 2015;21(5):670.

25. Touat M, Maisonobe $\mathrm{T}$, Knauss $\mathrm{S}$, et al. Immune checkpoint inhibitorrelated myositis and myocarditis in patients with cancer. Neurology. 2018;91(10):e985-e994.

26. Zimmer L, Goldinger SM, Hofmann L, et al. Neurological, respiratory, musculoskeletal, cardiac and ocular side-effects of anti-PD-1 therapy. European Journal of Cancer. 2016;60:210-225.

27. Alomari A, Rauch PJ, Orsaria M, Minja FJ, Chiang VL, Vortmeyer AO. Radiologic and histologic consequences of radiosurgery for brain tumors. Journal of neuro-oncology. 2014;117(1):33-42.

28. Colaco RJ, Martin P, Kluger HM, Yu JB, Chiang VL. Does immunotherapy increase the rate of radiation necrosis after radiosurgical treatment of brain metastases? Journal of Neurosurgery. 2016;125(1):17-23.

29. Hwang WL, Pike LRG, Royce TJ, Mahal BA, Loeffler JS. Safety of combining radiotherapy with immune-checkpoint inhibition. Nature Reviews Clinical Oncology. 2018;15(8):477-494.

30. Lehrer EJ, McGee HM, Peterson JL, et al. Stereotactic Radiosurgery and Immune Checkpoint Inhibitors in the Management of Brain Metastases. International journal of molecular sciences. 2018;19(10):3054.

31. Dubey D, David WS, Amato AA, et al. Varied phenotypes and management of immune checkpoint inhibitor-associated neuropathies. Neurology. 2019;93(11):e1093-e1103. 
32. Makarious D, Horwood K, Coward JIG. Myasthenia gravis: An emerging toxicity of immune checkpoint inhibitors. European Journal of Cancer. 2017;82:128-136.

33. Suzuki S, Ishikawa N, Konoeda F, et al. Nivolumab-related myasthenia gravis with myositis and myocarditis in Japan. Neurology. 2017;89(11):1127-1134.

34. Kimura T, Fukushima S, Miyashita A, et al. Myasthenic crisis and polymyositis induced by one dose of nivolumab. Cancer Science. 2016;107(7):1055-1058.

35. Johnson DB, Balko JM, Compton ML, et al. Fulminant Myocarditis with Combination Immune Checkpoint Blockade. New England Journal of Medicine. 2016;375(18):1749-1755.

36. Barroso-Sousa R, Barry WT, Garrido-Castro AC, et al. Incidence of Endocrine Dysfunction Following the Use of Different Immune Checkpoint Inhibitor Regimens: A Systematic Review and Meta-analysis. JAMA oncology. 2018;4(2):173-182.

37. Friedman CF, Proverbs-Singh TA, Postow MA. Treatment of the Immune-Related Adverse Effects of Immune Checkpoint Inhibitors: A Review. JAMA oncology. 2016;2(10):1346-1353.

38. Yoest JM. Clinical features, predictive correlates, and pathophysiology of immune-related adverse events in immune checkpoint inhibitor treatments in cancer: a short review. Immunotargets Ther. 2017;6:73-82.

39. Horvat TZ, Adel NG, Dang TO, et al. Immune-Related Adverse Events, Need for Systemic Immunosuppression, and Effects on Survival and Time to Treatment Failure in Patients With Melanoma Treated With Ipilimumab at Memorial Sloan Kettering Cancer Center. JOURNAL OF CLINICAL ONCOLOGY. 2015;33(28):3193-3198.

40. Abu-Sbeih $\mathrm{H}$, Tang $\mathrm{T}$, Ali $\mathrm{F}$, et al. The impact of immune checkpoint inhibitor-related adverse events and their immunosuppressive treatment on patients\&\#39; outcomes. Journal of Immunotherapy and Precision Oncology. 2018;1(1):7-18. 


\section{Curriculum Vitae}

Sophie Lan-Linh Duong

\section{Akademischer Werdegang}

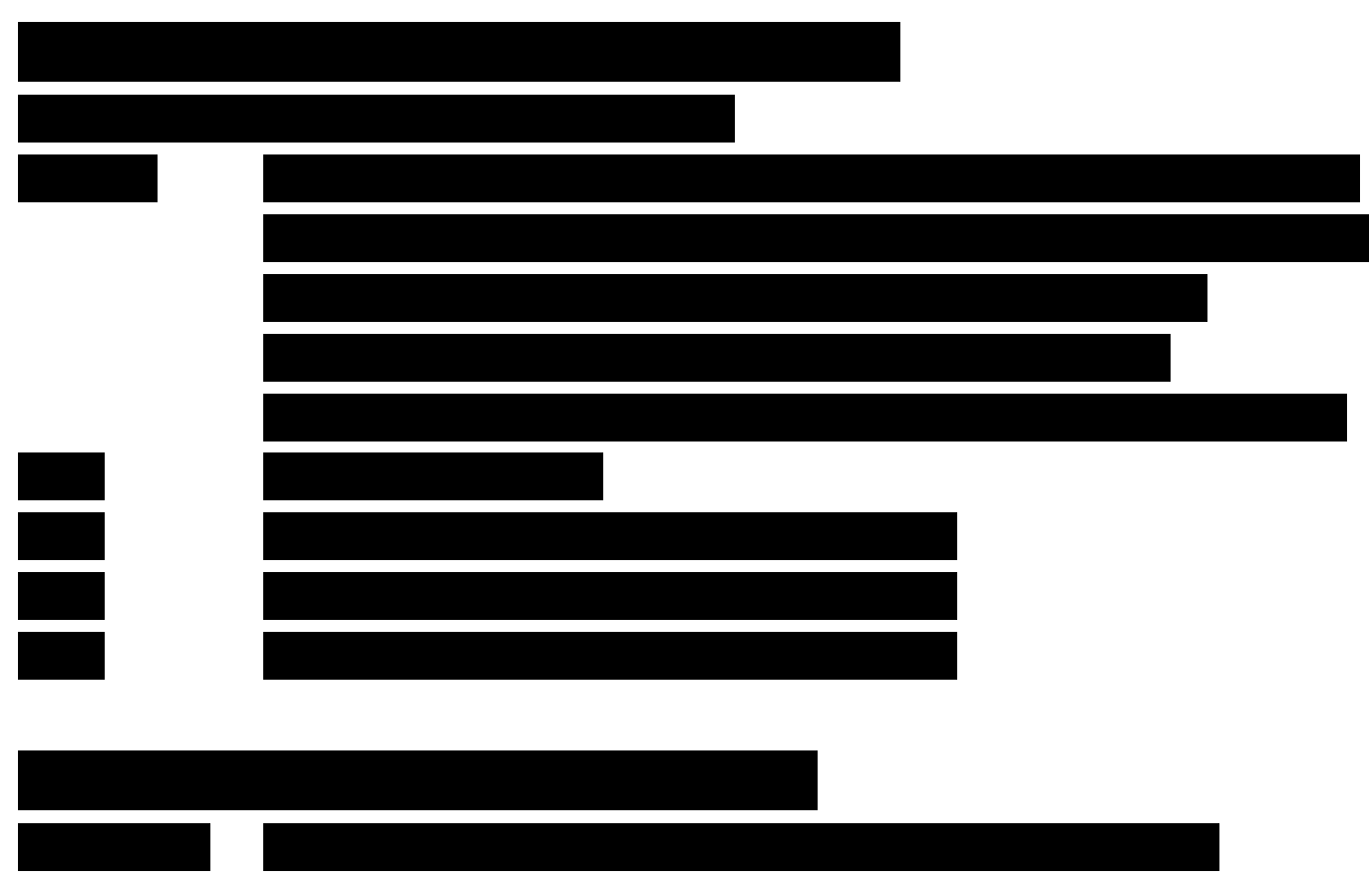

Klinische Erfahrung

PRAKTISCHES JAHR TERTIALE

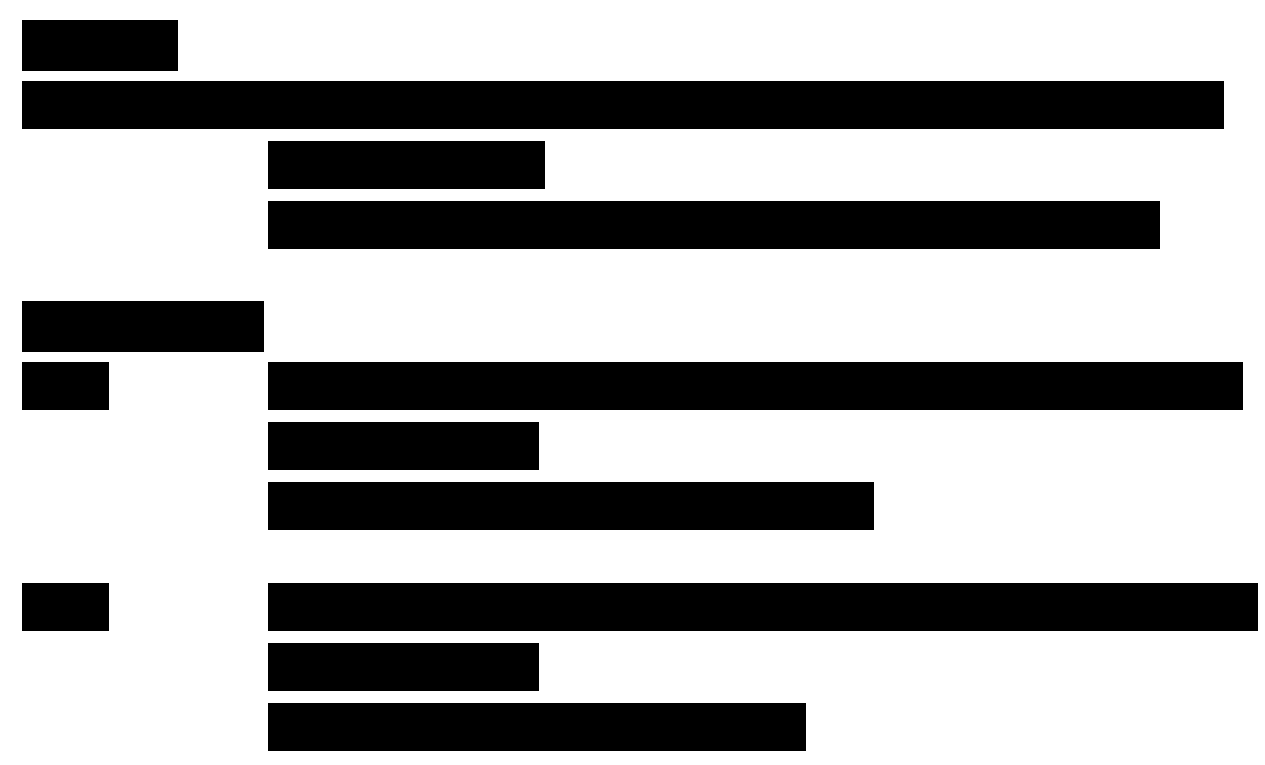




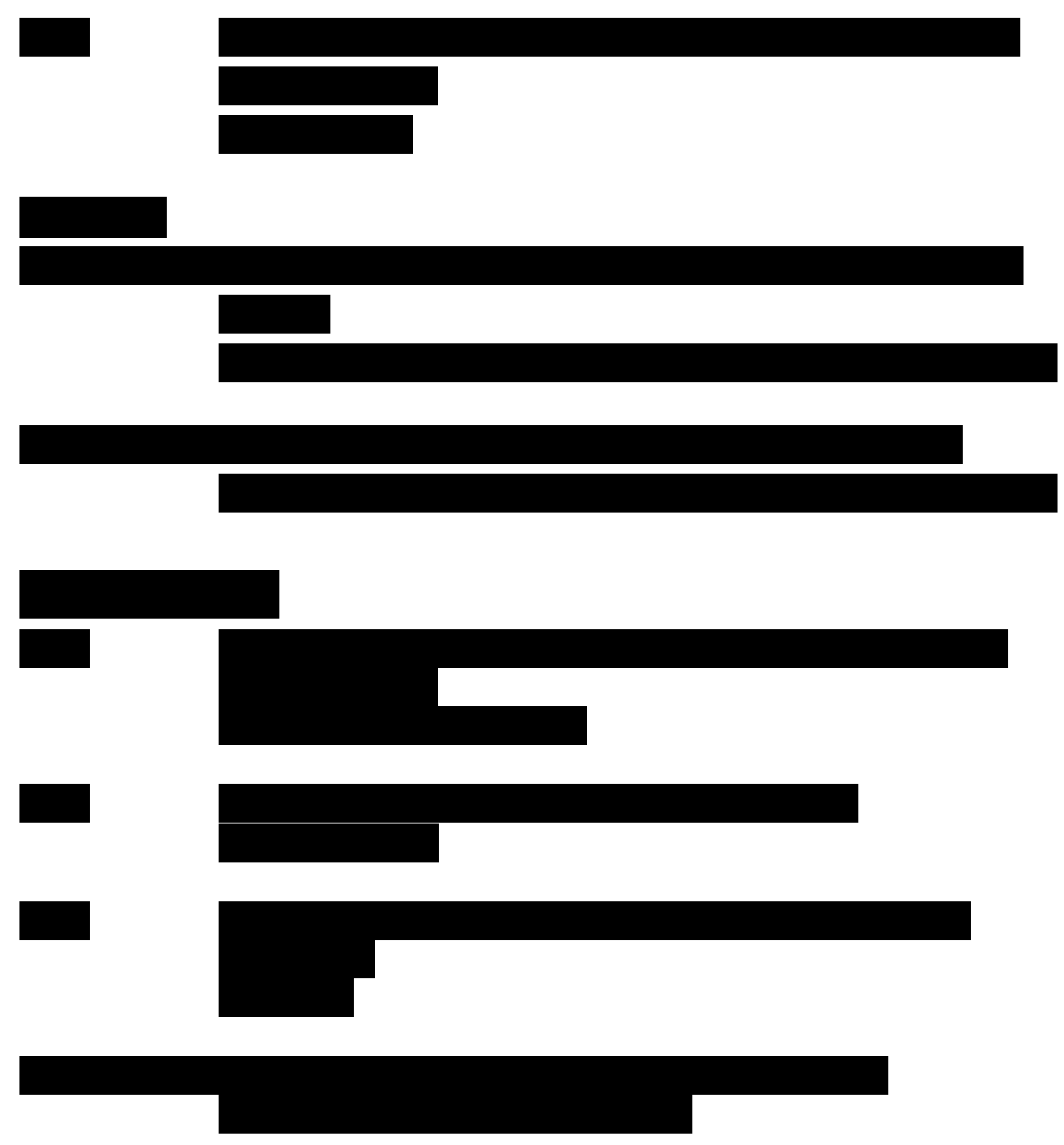

Forschungserfahrung
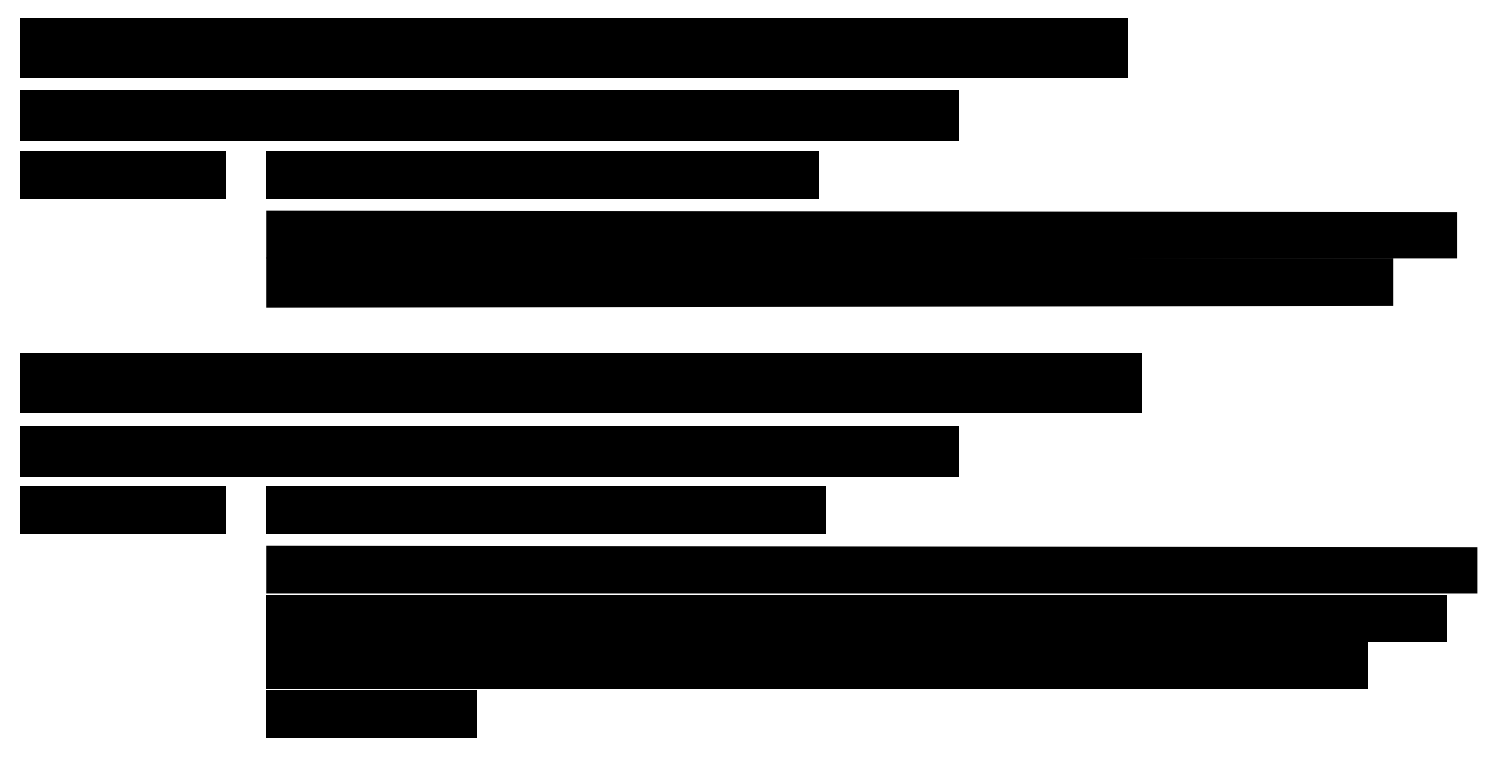


\section{Auszeichnungen}

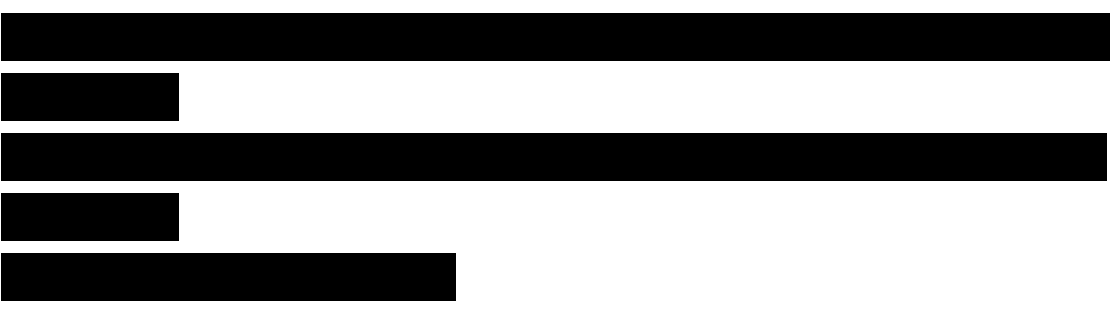

\section{Stipendien}
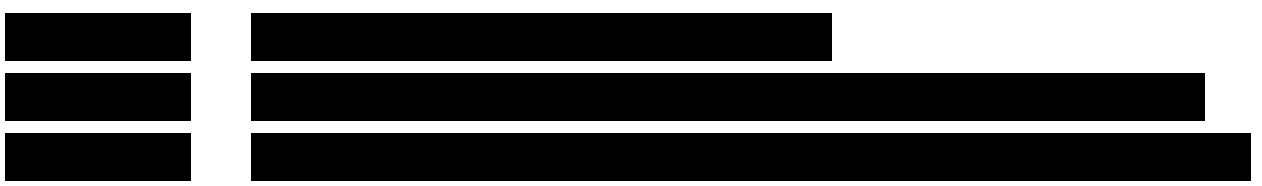

\section{Publikationen}

[1] Duong SL, Barbiero FJ, Nowak RJ, Baehring JM. Neurotoxicities associated with immune checkpoint inhibitor therapy. J Neurooncol. 2021 Apr;152(2):265-277. doi: 10.1007/s11060-02103695-w.

[2] Duong SL, Zierold S, Kramer R, Reincke M, Kerl-French K, Boehmerle W, Pavel M, Weckbach L, French LE, Knauss S, Heinzerling L. Spätfolgen nach Immuntherapie. Onkologe (2021). doi: 10.1007/s00761-021-00946-3.

[3] Kuo IY, Duong SL, Nguyen L, Ehrlich BE. Decreased Polycystin 2 Levels Result in NonRenal Cardiac Dysfunction with Aging. PLoS One. 2016 Apr 15;11(4):e0153632. doi: 10.1371/journal.pone.0153632.

Berlin, 04.12.2021

Ort, Datum

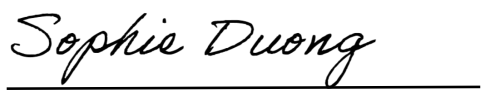

Unterschrift 


\section{Acknowledgments}
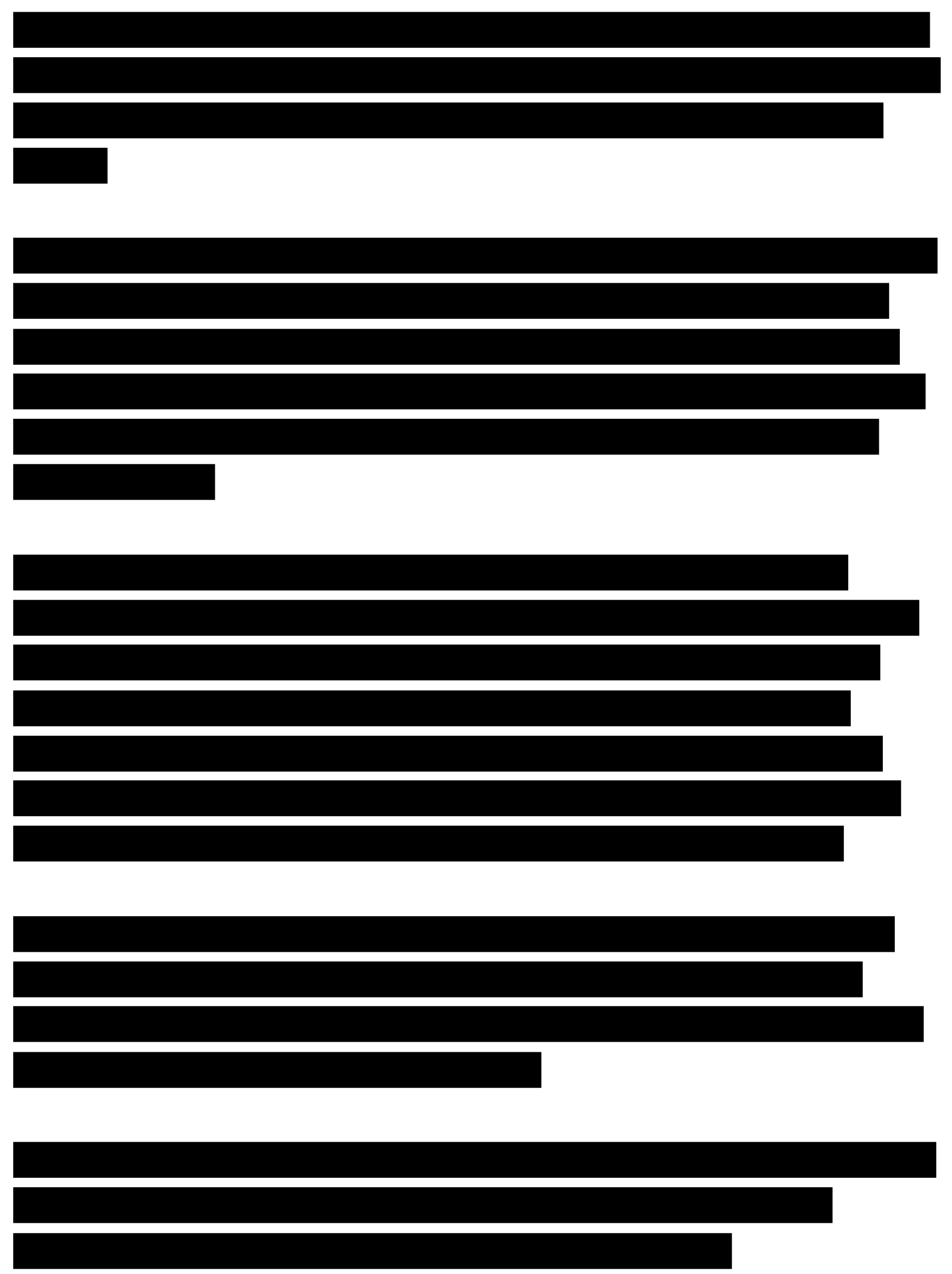


\section{Schriftliche Erklärung}

Ich erkläre ehrenwörtlich, dass ich die dem Fachbereich Medizin der Johann Wolfgang Goethe-Universität Frankfurt am Main zur Promotionsprüfung eingereichte Dissertation mit dem Titel

\section{Neurotoxicities Associated with Immune Checkpoint Inhibitor Therapy}

in dem Institut für Physiologie II (Sinnes- und Neurophysiologie) unter Betreuung und Anleitung von Prof. Dr. Jochen Roeper mit Unterstützung durch Prof. Dr. Joachim M. Baehring ohne sonstige Hilfe selbst durchgeführt und bei der Abfassung der Arbeit keine anderen als die in der Dissertation angeführten Hilfsmittel benutzt habe. Darüber hinaus versichere ich, nicht die Hilfe einer kommerziellen Promotionsvermittlung in Anspruch genommen zu haben.

Ich habe bisher an keiner in- oder ausländischen Universität ein Gesuch um Zulassung zur Promotion eingereicht. Die vorliegende Arbeit wurde bisher nicht als Dissertation eingereicht.

Vorliegende Ergebnisse der Arbeit wurden in folgendem Publikationsorgan veröffentlicht:

Duong, S.L., Barbiero, F.J., Nowak, R.J., Baehring, J.M., Neurotoxicities associated with immune checkpoint inhibitor therapy. Journal of NeuroOncology (2021). https://doi.org/10.1007/s11060-021-03695-w

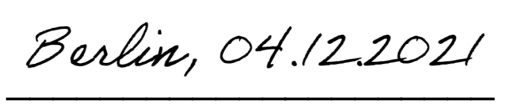

(Ort, Datum)

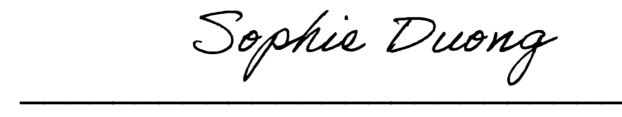

(Unterschrift) 